2014s-18

\title{
Multidimensional poverty in immigrant households: a comparative analysis within the Europe 2020 framework
}

\author{
Rosa Martínez, Jesús Ruiz-Huerta
}

\section{Série Scientifique \\ Scientific Series}

Montréal
Février 2014/February 2014

(C) 2014 Rosa Martínez, Jesús Ruiz-Huerta. Tous droits réservés. All rights reserved. Reproduction partielle permise avec citation du document source, incluant la notice $($ ).

Short sections may be quoted without explicit permission, if full credit, including (C) notice, is given to the source.
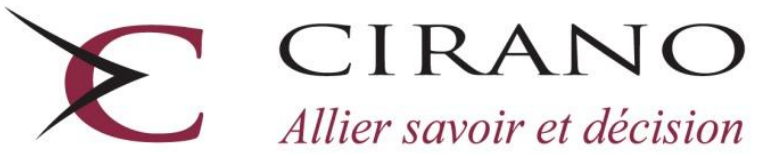

Allier savoir et décision

Centre interuniversitaire de recherche en analyse des organisations 


\section{CIRANO}

Le CIRANO est un organisme sans but lucratif constitué en vertu de la Loi des compagnies du Québec. Le financement de son infrastructure et de ses activités de recherche provient des cotisations de ses organisations-membres, d'une subvention d'infrastructure du Ministère de l'Enseignement supérieur, de la Recherche, de la Science et de la Technologie, de même que des subventions et mandats obtenus par ses équipes de recherche.

CIRANO is a private non-profit organization incorporated under the Québec Companies Act. Its infrastructure and research activities are funded through fees paid by member organizations, an infrastructure grant from the Ministère de l'Enseignement supérieur, de la Recherche, de la Science et de la Technologie, and grants and research mandates obtained by its research teams.

\section{Les partenaires du CIRANO}

\section{Partenaire majeur}

Ministère de l'Enseignement supérieur, de la Recherche, de la Science et de la Technologie

\section{Partenaires corporatifs}

Autorité des marchés financiers

Banque de développement du Canada

Banque du Canada

Banque Laurentienne du Canada

Banque Nationale du Canada

Banque Scotia

Bell Canada

BMO Groupe financier

Caisse de dépôt et placement du Québec

Fédération des caisses Desjardins du Québec

Financière Sun Life, Québec

\section{Gaz Métro}

Hydro-Québec

Industrie Canada

Investissements PSP

Ministère des Finances et de l'Économie

Power Corporation du Canada

Rio Tinto Alcan

Transat A.T.

Ville de Montréal

\section{Partenaires universitaires}

École Polytechnique de Montréal

École de technologie supérieure (ÉTS)

HEC Montréal

Institut national de la recherche scientifique (INRS)

McGill University

Université Concordia

Université de Montréal

Université de Sherbrooke

Université du Québec

Université du Québec à Montréal

Université Laval

Le CIRANO collabore avec de nombreux centres et chaires de recherche universitaires dont on peut consulter la liste sur son site web.

Les cahiers de la série scientifique (CS) visent à rendre accessibles des résultats de recherche effectuée au CIRANO afin de susciter échanges et commentaires. Ces cahiers sont écrits dans le style des publications scientifiques. Les idées et les opinions émises sont sous l'unique responsabilité des auteurs et ne représentent pas nécessairement les positions du CIRANO ou de ses partenaires.

This paper presents research carried out at CIRANO and aims at encouraging discussion and comment. The observations and viewpoints expressed are the sole responsibility of the authors. They do not necessarily represent positions of CIRANO or its partners. 


\title{
Multidimensional poverty in immigrant households: a comparative analysis within the Europe 2020 framework $^{*}$
}

\author{
Rosa Martínez $z^{\dagger}$ Jesús Ruiz-Huerta
}

\begin{abstract}
Résumé/abstract
The European 2020 Strategy has launched a novel indicator for monitoring poverty reduction over the current decade, simultaneously taking into account income, material deprivation and work intensity. The present paper uses this new indicator as a springboard for a discussion of the potential of a multidimensional measure, based on these three domains, to analyse the risk of poverty and social exclusion among immigrants. It is argued that the analytical insight and internal consistency of the new Europe 2020 indicator can be enhanced by a more structured measurement approach, relying on some recent advances generated by multidimensional poverty literature. The Alkire-Foster methodology provides a natural extension to the Europe 2020 indicator, which can usefully complement the picture drawn from the at-risk-of-poverty or social exclusion statistics. In the second part of the paper, these adjusted measures are used to analyse the multidimensional poverty profiles of immigrant households in Spain and other five developed countries, as well as the changes occurring since the beginning of the economic downturn. We try to show that the Europe 2020 indicator alone may not be sufficient to reflect the growing intensity of multidimensional deprivation among immigrants in some countries.
\end{abstract}

Mots clés/Keywords:: poverty, deprivation, social exclusion, unemployment, immigration

Codes JEL : J15, D31, I32

\footnotetext{
* XXI Encuentros de Economía Pública, Universitat de Girona, 30 and 31 January 2014.

The authors wish to acknowledge financial support from the Ministry of Science and Innovation (ECO201021668-C03-01). This paper is based on work carried out during our visit to the Centre Interuniversitaire de Recherche en Analyse des Organisations (CIRANO), Montréal, Canada, for whose hospitality and assistance we are extremely grateful. We would like to give special thanks to Geranda Notten, Andrew Heisz, Miles Corak, Brahim Boudarbat, Jean-Ives Duclos and François Vaillancourt for useful comments and invaluable help in navigating Canadian databases, and to Aurélie Tetoofa, Lily-Isabelle Alameh and Catherine Roch-Hansen for their excellent research assistance.

${ }^{\dagger}$ CIRANO and Universidad Rey Juan Carlos, Madrid, e-mail: rosa.martinez.lopez@urjc.es, Departamento de Economía Aplicada II, Facultad de Ciencias Jurídicas y Sociales, Po de los Artilleros S/N 28032, Madrid. $\$$ CIRANO and Universidad Rey Juan Carlos, Madrid, e-mail: jesus.ruizhuerta@ urjc.es, Departamento de Economía Aplicada II, Facultad de Ciencias Jurídicas y Sociales, Po de los Artilleros S/N 28032, Madrid.
} 


\section{Introduction}

In developed countries immigration is increasingly perceived as a structural phenomenon in an ever more globalised world. Over the last period of economic expansion, 2000-2005/06, migrant flows to OECD countries rose by over 33\%, which led to an increase of about 16 million persons in the migrant population living in the OECD in a very short period ${ }^{2}$. Many of these newcomers chose Spain as their final destination, making it the country with the largest relative increase in the migrant population in the years prior to the onset of the crisis. Ireland, Italy and Finland also faced huge rises in migrant arrivals during the same years.

Although the economic recession has significantly slowed down such inward flows, especially in certain countries, it is not sure that migration to the OECD countries will diminish much in the near future, and the return of immigrants to their origin countries does not seem to be very intensive ${ }^{3}$.

The incorporation of third-country nationals in the European Union has generated a lively debate in recent years, especially since the introduction, first in the Netherlands and then in other countries, of a new civic integration approach that constitutes in some ways a clear departure from more open previous policies ${ }^{4}$. In the United States and Canada, which have traditionally hosted large numbers of immigrants, growing attention has also been paid to the integration of the new waves of immigrants, perceived as more problematic than in the past ${ }^{5}$.

One important feature of the literature on the factors affecting the socioeconomic integration of immigrants in developed countries has been the move from the analysis of earnings assimilation that dominated initial studies, especially since the significant contributions made by Chiswick (1978) and Borjas (1985), to a more comprehensive evaluation framework that incorporates the disadvantages faced by immigrants in a number of relevant dimensions, such as education, employment, income, housing, access to public

\footnotetext{
2 Widmaier and Dumont (2011).

${ }^{3}$ Even during the first years of the crisis the number of immigrants increased, as the Spanish Labour Force Surveys show. Only since 2011 there has been a small decrease on this figure. See Angoitia and Tobes (2013) for a more detailed analysis.

${ }^{4}$ Goodam (2010), Jopkke (2007), Jacobs and Rea (2007).

${ }^{5}$ See for example Borjas (2006) for the United States or Picot and Sweetman (2005) for Canada.
} 
services or social relations ${ }^{6}$. At the same time, the factors explaining differences in economic outcomes have generated a lively discussion in Europe, with the relative role of (and the relationship between) migrant integration policies and general redistributive welfare state policies being at the core of many debates?

Although migrant integration programs remain under the national jurisdiction of the member states in Europe, important efforts have been made since 1999, when the Tampere program was adopted, to strengthen cooperation by defining common goals and basic principles for integration policies, as well as by identifying and sharing good practices in a variety of relevant domains. In accordance with the recommendation made by the 2010 Zaragoza Declaration and the new social targets established by the Europe 2020 Strategy, a great deal of attention is currently being paid to the agreement of a common set of indicators to monitor progress towards the integration of migrant households ${ }^{8}$.

Migrant integration is defined by the European Commission as "a dynamic, twoway process of mutual accommodation by all immigrants and residents of Member States" that involves at the same time economic, political and cultural aspects ${ }^{9}$. However there appears to be strong consensus on the central role of economic achievements in overall integration outcomes. This key role, clearly suggested by the wording of the eleven common basic principles for immigrant integration policies adopted in $2004^{10}$, has been further vindicated since the launching of the Europe 2020 Strategy, whose employment and social inclusion targets are held to be closely interrelated with migrant integration policies (European Commission, 2010b: 10, 18-19). In this regard, the new poverty

${ }^{6}$ See among others Boubtane et al. (2011), Giulietti et al. (2011), IDEAS (2009), Bhalla and McCormick (2009), Hickman et al. (2009), Pi Alperin (2008), Deutsch and Silber (2006), Aleksynka and Algan (2010) or Hildebrandt et al. (2012).

${ }^{7}$ On this question see Joppke (2010, 2007), Kraal et al. [eds.] (2009), Causa and Jean (2007), Jacobs and Rea (2007), Büchel and Frick (2005) and Penninx (2004). In a highly controversial paper Koopmans (2008) argued, using data for eight countries (Sweden, Belgium, the Netherlands, France, Germany, Austria, Switzerland and the United Kingdom), that the combination of active multicultural integration policies with generous welfare states have generated the deepest integration gaps in Europe. In contrast, countries with smaller welfare states and/or more assimilative integration policies tend to obtain better integration outcomes. Other studies have called into question these results, as they rely on data that are not genuinely comparable: see for example Jacobs et al. (2009). In Spain, see the review Presupuesto y Gasto Público number 64 (2010).

${ }^{8}$ An initial pilot study has already been released, in an attempt to assess to what extent the Zaragoza Declaration's set of common indicators of integration in four key areas (employment, education, social inclusion and active citizenship) can be derived from existing harmonized data sources, mainly Labour Force Surveys and EU-SILC microdata; see Kraszewska (2011) for more detail.

${ }^{9}$ European Commission (2010a), p. 160.

${ }^{10}$ See http://ec.europa.eu/ewsi/en/EU actions integration.cfm for the listing of these Common Basic Principles. 
indicator included in the Europe 2020 framework appears to be particularly suitable for monitoring progress towards the socioeconomic incorporation of migrant households, since it permits joint consideration of the risks arising from weak integration into the labour market and from low levels of income or material wellbeing.

However, the particular indicators and thresholds employed to summarize each dimension, as well as the aggregation strategy chosen to identify the official target group (a simple headcount union approach), may not necessarily represent the best choices to adequately monitor the risk of poverty and social exclusion of immigrant households (or other vulnerable groups) in every European country.

This paper directly addresses this issue by examining the applicability of the Europe 2020 approach to the analysis of the multidimensional poverty profile of immigrants in Spain, in comparison with a group of highly developed countries with a strong tradition of immigration (Italy, France, Germany, the United Kingdom, and Canada). In the first part of the paper we will discuss the strengths and weaknesses of the new Europe 2020 headline poverty indicator under the lens of multidimensional poverty literature, as a way to explore its internal consistency and analytical insight, bringing to light some aspects that could be problematic when used in the context of highly developed countries.

Taking for granted the three dimensions included in the new Europe 2020 indicator, a revised multidimensional poverty index is derived following the Alkire-Foster (2011a,b) approach. This index is then used to analyse multidimensional poverty levels and profiles of immigrant households in the selected group of old and new immigration countries, using EUSILC data. In the case of Canada, a non-EUSILC country, we use microdata from the 2009 Survey of Labour and Income Dynamics in order to construct the multidimensional poverty index, taking advantage of the new material deprivation module collected since the year 2008 for Ontario residents.

Finally, the paper provides new evidence on how the current economic crisis is affecting the multidimensional poverty risk of immigrants in Spain and other countries, using EUSILC data for the period 2008-2011. To that end, we analyse the impact of changes on each domain of the overall poverty level during the economic downturn, both 
in immigrant and native households. The paper concludes with some final remarks on the policy implications of our findings and some possible routes for further research.

\section{Analysing poverty within the Europe 2020 framework: key issues}

The multidimensional approach to poverty and wellbeing has become increasingly influential over the last few decades in both developed and less developed countries. At the European level, it is now widely recognized that conventional low-income indicators have some important drawbacks as benchmarks to monitor progress in combating poverty, for a number of reasons which range from the purely relative nature of conventional thresholds to the well-known limitations of income, as currently measured by household surveys, to adequately capture the amount of resources available to the household. Consistent empirical evidence on the limited overlap between income poverty and material deprivation, whatever the procedure chosen to summarize the two phenomena, has contributed to highlight the necessity of a new approach to analyse poverty and social exclusion at the European level ${ }^{11}$.

In this context, the new EU strategy for jobs and smart, sustainable and inclusive growth, known as the Europe 2020 strategy $^{12}$, has taken a great leap forward by proposing a novel indicator for monitoring the reduction of poverty over the current decade. It is worth noting that the poverty reduction goal was initially defined on the basis of the atrisk-of poverty indicator alone ${ }^{13}$, but the target was finally agreed in terms of the new and wider "at-risk-of-poverty or social exclusion" (AROPE) indicator, defined on a multidimensional basis and simultaneously taking into account low income, material deprivation and employment deprivation.

Although the new target is generally seen as a step towards a multidimensional perspective of poverty, more consistent with the social inclusion policy approach prevalent in the EU, its final formulation has been criticized by some experts, who consider the final

\footnotetext{
${ }^{11}$ See among others Fusco, Guio and Marlier (2013, 2010a, 2010b), Alkire and Apablaza (2012), de Neubourg et al. (2012), Nolan and Whelan (2011, 2010), Berthoud and Bryan (2010).

${ }^{12}$ In June 2010, the European Council approved this strategy, designed to be the successor to the 2000 Lisbon Strategy, as representative of the direction that Europe should take to "emerge stronger from the economic and financial crisis", see European Commission (2010b), p.2.

13 The exact wording of the initial formulation of Europe 2020 Strategy was that "the number of Europeans living below national poverty lines should be reduced by $25 \%$, lifting over 20 million people out of poverty", European Commission (2010b: 32).
} 
proposal to be "fuzzier" and less ambitious than the original ${ }^{14}$. In any case, it is important to highlight that the new headline indicator must be regarded as a flexible benchmark agreed within the context of the so-called European "open method of coordination", which member states are free to adapt to national circumstances and priorities when setting their national targets.

We examine below in greater detail the indicator through the lens of the multidimensional poverty measurement literature, while still keeping in mind the restrictions derived from the origin, context and intended use of the "at-risk-of-poverty or social inclusion" figures ${ }^{15}$. To that end, we review the features of the new measure with regard to each of the different steps involved in multidimensional poverty measurement, from the selection of dimensions to the indicators and thresholds used and the aggregation method finally applied to obtain an overall summary measure.

\section{a) Dimensional structure}

As explained above, the new index is based on three main facets (low income, material deprivation and low work intensity), in contrast to the standard income approach used when the first European programs to fight poverty were launched in the 1980s. It is worth underlining that the new index is intended to capture not only poverty, but also the much wider concept of "social exclusion". This approach is in line with the growing emphasis of European social policy on the "social inclusion" concept, which covers dimensions far beyond income or economic poverty, as health, employment, education, political participation or social contacts.

On the other hand, the new measure is not aimed at determining the precise levels of "poverty" or "social exclusion", but rather the "risk" of falling into these situations. This change of emphasis can be read as a certain loss of confidence in the capacity of income alone to adequately reflect poverty in the European Union, especially when combined with purely relative income thresholds set at the national level. Furthermore, it must be linked to

\footnotetext{
${ }^{14}$ Nolan and Whelan (2011), for instance, argue that the new headline indicator increases the size of the target group by $50 \%$, thus dropping the reduction aimed for from a quarter to a sixth.

${ }^{15}$ This means taking into account that measures used to monitor poverty trends in a policy oriented framework, such as the Europe 2020 Strategy, have a number of desirable properties that preclude the use of excessively data-intensive and overly technical approaches. See Atkinson and Marlier (2010) for a detailed discussion of this issue.
} 
the growing interest in material deprivation indicators as a complementary strategy to identify the poor, both inside each country and across countries, given their closer relationship with differences in living standards in an enlarged and much more heterogeneous EU.

Given the broad scope of the targeted concept, the use of only three dimensions is a remarkably parsimonious choice. Thus, the new index has wisely avoided the "explosion of concern" of many indiscriminate listings of problems, which, as Sen has indicated, have contributed to keeping some experts on poverty and deprivation removed from the social exclusion debate (Sen, 2000: 2), while at the same time offering poor guidance to policymakers ${ }^{16}$. However, as has occurred with other composite indicators developed to monitor social trends at the international level, such as the Human Development Indicator, the Economic Welfare Index or the new Multidimensional Poverty Index, the proposal has also stimulated close scrutiny and a wide range of criticisms. Atkinson and Marlier (2010: 32) have stressed this fact, pointing out that " $(t)$ he adoption of the social inclusion headline target puts the EU social indicators under the spotlight".

It can be argued that the choice of these three dimensions makes sense if we consider the new index as an adaptation of the traditional risk-of-poverty indicator, which tries to adjust the poverty concept to the wider notion of social exclusion without totally departing from the conventional low income indicator. In this context, the use of income and deprivation indicators would confirm the trend, increasing over the last decade, towards combining the two approaches when analysing poverty. On the other hand, the introduction of the work intensity dimension contributes to increased visibility and gives political priority to the unemployment problem, which is fully consistent with the first objective of the EU 2020 Strategy and with the shared view that jobs are crucial to minimize the risk of poverty and make easier social inclusion. Furthermore, using the household as the unit of analysis to evaluate the indicator helps to emphasize the importance of the family distribution of unemployment, which has been shown to play a decisive role in explaining the relationship between unemployment and poverty ${ }^{17}$.

\footnotetext{
${ }^{16}$ As stressed by Burstein (2005: 13), when analyzing the groups at risk of social exclusion in Canada: "The range of policies engaged by the less "abstemious" descriptions of exclusion are daunting. At their widest, they cannot be distinguished- except in their targeting - from social policy in general".

${ }^{17}$ For Spain, see among others Gradín, Cantó and del Río (2012), Gradín and del Río (2013), Ayala, Cantó and Rodríguez (2011) or García Serrano and Malo (2008).
} 
The three dimensions considered can also be seen as especially useful to study immigrant integration. Employment is in fact regarded as "a key part of the integration process" in the Common Basic Principles for Immigrant Integration Policy adopted by the Justice and Home Affairs Council in 2004. On the other hand, the sixth basic principle highlights the importance of access for immigrants "to public and private goods and services, on a basis equal to national citizens" as "a critical foundation for better integration" ${ }^{18}$. This implies trying to avoid income poverty and deprivation among immigrants.

Although the integration of immigrants is a long-term process involving other aspects that go beyond income and jobs, the ability to avoid poverty and achieve a minimum standard of living can be easily seen as vital for integration in the remaining domains. While the new "at-risk-of-poverty or social exclusion" measure had not yet been included in the initial list of indicators held to monitor the migrant integration process, as proposed in the 2010 Zaragoza Declaration, it should be noted that it was added to results presented in the first pilot study carried in that field (Kraszewska, 2011: 11).

Nevertheless, the dimensional structure of the new poverty headline indicator has been questioned by authors such as Nolan and Whelan (2011), who point out that the inclusion of low work intensity households in the target population results in a more imprecise and less internationally differentiated poverty profile ${ }^{19}$. In their view, combining low income and material deprivation constitutes a step in the right direction when trying to enhance the poverty measure, while adding the work intensity measure weakens the final indicator. Although this point deserves careful consideration (and possibly deeper countrywide studies), it is worth noting that, as stated above, the new measure is aimed at assessing the risk of poverty and social exclusion, rather than quantifying the actual number of the poor.

\footnotetext{
${ }^{18}$ European Commission (2007).

${ }^{19}$ As Nolan and Whelan (2011: 18) put it, "At a conceptual level, the argument for including in the target population persons living in households that are jobless but are neither on low income (relative to their own country's median income) not materially deprived (relative to a common EU wide standard) is unclear. Joblessness might be better thought of as a factor leading to income poverty or material deprivation than as an indicator of poverty. Empirical analysis then shows that the group added to the target population by the inclusion of the joblessness/low work intensity criterion has a relatively high proportion from the professional and managerial classes and a relatively low proportion from the working class, and that being in this group is not associated with high levels of economic stress".
} 
It could thus be argued that the inclusion of the employment indicator would allow policymakers to identify those households which, despite not suffering low income nor material deprivation at present (because they are receiving temporary transfers or are relying on savings), do in fact have a problem of lack of economic autonomy and a pronounced vulnerability to poverty and social exclusion, if the low work intensity situation persists. On the other hand, there is extensive evidence on the linkage between unemployment and "social unrest", particularly in periods of economic crisis. ${ }^{20}$

\section{b) Indicators and thresholds}

Having selected the relevant dimensions, any multidimensional measure must determine which specific indicators and thresholds should be used to identify the poor, as well as the weights and identification function used to combine the results obtained in each domain.

Table 1 shows the variables and cutoffs chosen to summarize each dimension in the Europe 2020 "at-risk-of-poverty or social exclusion" indicator. Low income is measured through the conventional at-risk-of-poverty rate based on each country's median income, so that the target population is defined within each country as those falling below national income standards, which can differ considerably among countries in the current enlarged EU. Taking the EUSILC data for 2011, the average low income ratio was $16,9 \%$ for the EU-27 area, and the lowest values were around 10\% and 11\% in the Czech Republic and the Netherlands, while the highest was close to 22\% (in Romania, Bulgaria, Spain and Greece).

This traditional European method of setting income poverty lines has become increasingly controversial within the $\mathrm{EU}$, due both to its low sensitivity to changes in median income over time and to geographical differences in real standards of living across the enlarged EU. The current economic recession has shown to what extent poverty statistics can exhibit paradoxical results, as observed in Latvia, where the index changed from $25,6 \%$ in 2008 to $19,3 \%$ in 2011, while the median income with regard to purchasing power fell from 7.257 to 5.666 euros over the same period. Furthermore, it is far from clear

\footnotetext{
${ }^{20}$ Different papers show the clear negative incidence of unemployment on physical and mental health. See, among others, Urbanos y González (2013), or Jin et al (1995).
} 
that national boundaries continue to provide the most pertinent context to assess the average standard of living for poverty comparison within the European Union.

Table 1

Dimensions, indicators and cut-offs used in the Europe 2020 "at-risk-of-poverty or social exclusion" measure

\begin{tabular}{|c|c|c|c|}
\hline Dimension & Indicators & Thresholds & $\begin{array}{l}\text { Reference } \\
\text { population }\end{array}$ \\
\hline $\begin{array}{l}\text { Low } \\
\text { income }\end{array}$ & $\begin{array}{l}\text { Household disposable income in the } \\
\text { calendar year previous to the survey year }{ }^{(1)} \text {, } \\
\text { adjusted using modified OECD scale. }\end{array}$ & $\begin{array}{l}60 \% \text { national } \\
\text { median income. }\end{array}$ & People of all ages. \\
\hline $\begin{array}{l}\text { Material } \\
\text { deprivation }\end{array}$ & $\begin{array}{l}\text { The household cannot afford } \\
\text { 1) To pay rent or utility bills. } \\
\text { 2) Keep home adequately warm. } \\
\text { 3) Face unexpected expenses. } \\
\text { 4) Eat meat, fish or a protein equivalent } \\
\text { every second day. } \\
\text { 5) A week's holiday away from home. } \\
\text { 6) A car. } \\
\text { 7) A washing machine. } \\
\text { 8) A colour TV. } \\
\text { 9) A telephone. }\end{array}$ & $\begin{array}{l}4+\text { deprivations } \\
\text { out of a list of } 9 \\
\text { items. }\end{array}$ & People of all ages. \\
\hline $\begin{array}{l}\text { Low work } \\
\text { intensity }\end{array}$ & $\begin{array}{l}\text { Work intensity of adults aged 18-59, } \\
\text { excluding students aged 18-24, during the } \\
\text { past year. }\end{array}$ & $\begin{array}{l}20 \% \text { of total } \\
\text { work potential in } \\
\text { the household. }\end{array}$ & $\begin{array}{l}\text { People 0-59 years } \\
\text { old. }\end{array}$ \\
\hline
\end{tabular}

Notes: (1) In United Kingdom the current income is annualised and aims to refer to the current calendar year. In Ireland, the income reference period is the last twelve months.

Source: Elaborated by the authors on the basis of Eurostat definitions, available at http://epp.eurostat.ec.europa.eu/portal/page/portal/europe 2020 indicators/headline indicators

As Berthoud (2012: 3) has argued, an alternative view is that "(...) people all over Europe are aware of, and implicitly compare themselves with, the living standards prevalent across the union". Nevertheless, no consensus has emerged so far on the most adequate reference group for poverty assessment at the European level, with some experts favouring national (and even regional) relativities whilst others support EU-wide poverty lines or even intermediate approaches ${ }^{21}$.

\footnotetext{
${ }^{21}$ See, among others Berthoud (2012), Whelan and Maitre (2009a,b).
} 
By contrast, material deprivation is assessed using a common European-wide set of items, originally developed by Guio (2009), covering the enforced lack of a number of goods or activities which range from a colour TV to a week's holiday away from home (see Table 1). Using this scale, a household is deemed to be deprived if the reported (unweighted) number of deprivations is above a given material deprivation threshold (the same in every member state). It should be noted that the original list is to be updated from 2013 onwards as a result of the in-depth analysis of the 2009 special material deprivation module undertaken under European sponsorship (Guio, Gordon and Marlier, 2012), which showed that some of the items currently included in the European material deprivation indicator did not pass the relevant validity and reliability tests in many countries ${ }^{22}$.

The chosen cut-off of four or more items out of the set of nine listed in Table 1 is intended to capture severe material deprivation according to the Eurostat concept, yielding an overall rate of $8,8 \%$ in year 2011 for the EU-27 area. National rates are strongly related to median income, a proxy for an EU-wide measure of poverty ${ }^{23}$, and as such exhibit a huge variation among countries, with values of over $20 \%$ in most of the poorer new member states (with a maximum of $43,6 \%$ in Bulgaria), but below 3\% in Luxembourg or the Scandinavian area.

The description above should serve to highlight that the inclusion of the two abovementioned poverty indicators in the new measure, in their present form, is not merely a way of combining an income and a material deprivation approach to poverty (or an indirect and a direct method to identify the poor, to use the well-known distinction made by Ringen, 1987), but also a sort of mixture of relative and absolute considerations when delimiting the target population.

Whether this should be seen as an "encouraging" development of the traditional European analytical framework (Fusco, Guio and Marlier, 2010²4), as a partial advance still

\footnotetext{
${ }^{22}$ As a result of this wide-ranging study, a new list of 13 indicators (18 for children) have been collected since the 2013 wave. The list for the whole population excludes the items related to the enforced lack of a television set, a washing machine and a telephone, and adds seven new deprivation questions, five of them to be asked at the individual level. See Guio, Gordon and Marlier (2012) for more details on this question.

${ }^{23}$ Fusco, Guio and Marlier (2010: 138) have shown that the correlation between national material deprivation rates and EU-wide based income poverty rates is close to 0,80, compared with approximately 0,1 for standard national income poverty rates.

${ }^{24}$ Fusco, Guio and Marlier (2010), p. 37: "In terms of national and EU reporting, the chapter clearly shows the complementarity of income poverty and material deprivation measures. So, to provide a much better picture of a country's situation with regard to 'poverty' (especially in the context of international
} 
needing further adjustments (Nolan and Whelan, 2011: 2925), or as an "anomaly" leading to "a confusing discourse" and puzzling implications for policymaking (Gilbert, 2012: 391"26) is open to debate. For now, it should be enough to draw attention to the fact that, given the indicators and thresholds chosen to summarize these two dimensions, many older EU member countries will tend to show large groups of people receiving low incomes (according to national standards) but not reporting material deprivation, whilst the opposite will be true in new, poorer, EU member countries.

Regarding the analysis of migrant integration in rich western European countries, such as Germany, France or even Spain, the material deprivation threshold used in the new Europe 2020 measure is most probably too strict to serve as a meaningful benchmark in the analysis of groups at risk of poverty and exclusion.

Finally, low work intensity status is measured on the basis of the time worked during the previous year by all adults aged 18 to 59 (excluding students aged 18-24), divided by the potential working time of the same working age household members. A cut-off is then employed to identify as deprived all individuals under 60 who live in households with a working intensity below 0,20 for working age adults. On average, the low work intensity rate reached a value of $10 \%$ in the EU-27 in 2011, ranging between values of $6 \%$ for Cyprus and Luxembourg to ratios above $12 \%$ in Belgium, Spain, Hungary, Latvia and Lithuania. It must be stressed that the low work intensity indicator is not defined for people aged sixty or above, who are not taken into consideration in the computation of this figure. This can pose a problem when attempting to check the robustness of results for different identification and aggregation strategies, since the number of dimensions effectively considered is not the same for those below and above 60. This is why we restrict the empirical analysis to people aged 60 or under, which on the other hand makes sense

comparisons), it is important that national income poverty rates be systematically published with the related national income poverty thresholds (in Purchasing Power Parities) and that they be systematically accompanied with national material deprivation rates. This should be kept in mind when monitoring the social dimension of the new Europe 2020 Strategy, which is to replace the 2000-2010 Lisbon Strategy. In this respect, the new EU target on social inclusion adopted in June 2010 is quite encouraging”.

${ }^{25}$ Nolan and Whelan, 2011, p. 29 “(...) combination of low income and deprivation can contribute to the development of appropriate targets. While looking at those who are either on low income or reporting significant deprivation has a value, we have argued that it would also be valuable to identify the sub-set of persons and households meeting appropriate income and deprivation criteria: this could serve to identify a priority group as countries frame their individual contributions to meeting the overall EU target".

${ }_{26}$ Gilbert (2012), p. 391: "Findings that show that a fair proportion of the EU countries have lower levels (or risks) of poverty, yet higher levels of material deprivation than many other countries, present policy makers with a confusing discourse on the relationship between poverty and material deprivation -as these terms are commonly understood." 
when analysing immigrant integration in different countries. But it would be worthwhile to explore variants of this indicator that can be extended to the whole population.

\section{c) Identification approach}

An important feature of any multidimensional measure, which does not arise in the unidimensional framework, is the need to decide the identification approach used to determine who are the multidimensionally poor, once identified those individuals or households considered "poor" or "deprived", regarding separately at each dimension. Should we identify the poor as those deprived in at least one dimension, following what the literature has called a "union approach"? Or, by contrast, should only those falling below the threshold in each of the $k$ dimensions be deemed to be poor -an "intersection approach"? As many authors have stressed, the adequacy of a union versus an intersection method, or some intermediate strategy lying in between these two extremes, depends ultimately on the dimensions selected and the nature of their interrelationships ${ }^{27}$.

The identification method used when constructing the "at-risk-of-poverty or social exclusion" measure is clearly based on a union approach, since an individual is considered to be at risk as long as he/she has low income, or suffers material deprivation, or lives in a very low work intensity household. The implicit assumption behind this approach is that it is necessary to reach a minimum level in each of the three dimensions to avoid the risk of poverty and exclusion, or to put it in other words, that having, say, high work intensity cannot compensate for having low income or living in material deprivation.

As rightly expressed by Tsui (2002: 74), “(t)his formulation, in a sense, emphasizes the essentiality of each attribute. (...) In the final analysis, how reasonable the identification rule is depends, inter alia, on the attributes included and how imperative these attributes are to leading a meaningful life". In the AROPE construct, the rational for this union approach can be arguably found in the purpose of evaluating the notion of "risk", rather than an actual situation of poverty or exclusion. Nevertheless, it is essential to enquire to what extent these risk factors overlap in different social groups and how this should affect the final assessment. From the point of view of a policy maker, a rate of poverty or social

\footnotetext{
${ }^{27}$ And in particular, to what extent the different attributes can be considered to be substitutes or complements in determining poverty status. See, among others, Duclos, Sahn and Younger (2006), Atkinson (2003), or Bourguignon and Chakravarty (2003).
} 
exclusion among immigrants of, say, 33\%, may have very different implications depending on whether that figure describes a group suffering simultaneously joblessness, low income and material deprivation, or three $11 \%$ non-overlapping groups, each of them deprived in one dimension but making do in the other two.

Thus, even if we accept that a simple union approach serves well the objective of providing an estimate of the size of the "at risk" population, other complementary measures based on an intermediate or even an intersection approach would be needed to analyse differences in intensity or deprivation profiles. Although Eurostat offers data on the breakdowns according to the intersections between sub-populations of the Europe 2020 indicator of poverty and social exclusion, the question of how differences among countries with regard to the extent to which these three dimensions overlap should be interpreted remains unsolved. Moreover, the severity of the material deprivation threshold currently used leads to identify very small groups as deprived in that domain in old member countries, thus undermining the usefulness of intersecting the three dimensions.

\section{d) Aggregation approach}

Following the classical distinction established by Sen, the aggregation step refers to the function used to summarize the overall poverty level in a given society or group, once those qualifying as poor or deprived have been adequately identified. Although a number of commonly accepted desirable properties and the corresponding axiomatically characterized measures have been proposed both in the unidimensional and the multidimensional poverty literature, "counting the poor" remains by far the procedure most widely used when constructing poverty indices, both in policy-oriented reports and in applied empirical work. The main advantages of such a counting approach, which Atkinson compared to its social welfare counterpart in a much quoted article ${ }^{28}$, are of course its simplicity and ease of interpretation, compared to other alternatives.

However, the headcount measures have also well-known limitations when making comparisons among groups or over time, since they are not able to reflect the depth of the shortfalls suffered by those below the threshold, nor the extent of inequality among the poor. In the multidimensional framework, the headcount ratio also involves implicitly

${ }^{28}$ See Atkinson (2003). 
assigning equal weights to the various dimensions, which can be a questionable assumption when including domains with very different impacts on the concept measured.

The Europe 2020 risk of poverty indicator provides a simple headcount measure based on the three dimensions described above, since it simply shows the number of people at risk of poverty or social exclusion (defined as those who fall below at least one of the three dimensional cut-offs, as seen above) as a percentage of the total population. Thus, it is neither sensitive to the number of deprived dimensions of those identified as poor nor to the size of the gaps within each domain. It means that the index does not change if, for instance, a household having only low income in year $t$ begins to suffer material deprivation in year $t+1$, since it has been already "counted" as an at-risk household. The same happens if redistribution occurs among the poor, so that income-or work- is transferred from the least deprived to those situated at the very bottom of the scale.

To sum up, the new poverty headline indicator adopted by the Europe 2020 Strategy clearly represents a step forward in the direction of measuring a broader concept of social inclusion, more consistent with the European policy making framework. However, there is still room to supplement or adapt the basic indicator to improve its usefulness when analysing vulnerability to poverty and social exclusion in a particular subset of European Union countries. A productive way to do so may be to insert the Europe 2020 indicator into a more general class of multidimensional poverty indices, flexible enough to permit robustness of conclusions to be checked when a set of basic parameters are modified.

In our view, the Alkire-Foster family of measures provides the most suitable approach to support this generalization within the Europe 2020 framework. Although some other interesting multidimensional measures exist in the literature, the A-F measures have certain properties that make them a good choice to analyse poverty and social exclusion in the European context. Specifically, they can be used with union, intersection or intermediate identification approaches, as well as with equal or different dimensional weights, they can show the intensity, and not only the extension, of multidimensional poverty, can fulfil a number of useful axioms, including subgroup decomposability, and, last but not least, can be applied to categorical, and not only to continuous, variables, thus widening the range of indicators that can be included in the measure. As it is well known, 
the Alkire-Foster measures have been constructed on the basis of Sen's capability approach, with a special focus on measuring poverty in developing countries, but have also been used in the context of rich countries in some recent empirical work ${ }^{29}$.

\section{Methodology and data description}

In this section we summarize and explain the basic data, measures and methodological choices used in the empirical analysis. We first describe briefly the AlkireFoster measures following the notation introduced by Alkire and Foster (2011a, 2011b). We then explain the options selected and the features and limitations of the datasets used.

\section{a) The Alkire-Foster family of multidimensional measures}

The Alkire-Foster class of multidimensional measures can be described as a parametric set of indices which, like many others developed in recent literature, represent in some ways a multidimensional generalization of the original Foster, Greer and Thorbecke (1984) poverty measures, given the role assigned to the concept of the normalized poverty gap.

In formal terms, let us consider a population of $1,2, \ldots, \mathrm{n}$ individuals, whose achievements are measured across $1,2, \ldots, \mathrm{d}$ different dimensions. One or various indicators that can be either cardinal or categorical variables represent each dimension. Against this background, let $\mathrm{y}=\left[\mathrm{y}_{\mathrm{ij}}\right]$ be the $\mathrm{n} \times \mathrm{d}$ matrix of achievements of a given population, where each row shows the values corresponding to individual $\mathrm{i}$ across the $\mathrm{d}$ dimensions, and each column contains the marginal distribution of a specific dimension $j$ across the entire population. Each of the elements $y_{i j}$ in the matrix represents the achievement of individual $i$ in dimension $j$. In the most general case, a vector of dimensional weights intended to allow different weighting schemes can be defined as: ${ }^{30}$

$$
w=\left(w_{1}, w_{2}, \ldots, w_{d}\right), \text { so that } \sum_{j=1}^{d} w_{j}=d
$$

\footnotetext{
${ }^{29}$ See for example Whelan, Nolan and Maitre (2012), or work in progress by Alkire and Apablaza (2012). For developing countries, a well-known application of this methodology is the Multidimensional Poverty Index developed by the Oxford Poverty \& Human Development Initiative to substitute the Human Poverty Index; see Alkire and Santos (2010) for a detailed explanation of the MPI structure and indicators.

30 The weights can be also normalized to sum up to 1, see Alkire, Roche and Seth (2011).
} 
Let us suppose that $z=\left(z_{1}, z_{2}, \ldots, z_{d}\right), z_{j}>0$ for all $j=1,2, \ldots, d$, contains the vector of dimensional deprivation cut-offs, used to identify individuals suffering deprivation in each domain. For a given set of thresholds, a deprivation matrix $g^{0}=\left[g_{i j}^{0}\right]$ can be defined as:

$$
\begin{array}{ll}
g_{i j}^{0}=w_{j}\left(\frac{z_{j}-y_{i j}}{z_{j}}\right)^{0} & \text { if } y_{i j}<z_{j} \\
g_{i j}^{0}=0 & \text { if } y_{i j} \geq z_{j}
\end{array}
$$

Which yields:

$$
g_{i j}^{0}=\left[\begin{array}{lll}
w_{j} & \text { if } & y_{i j}<z_{j} \\
0 & \text { if } & y_{i j} \geq z_{j}
\end{array}\right.
$$

From $g^{0}$ a column deprivation count vector $\mathrm{c}$ is then derived where each entry summarises the weighted number of deprivations, or capability failures, suffered by the $i$-th individual, $c_{i}=\sum_{j=1}^{d} g_{i j}^{0}$.

To identify the multidimensionally poor, a poverty cut-off $k, 0<k \leq d$, has to be applied to the column vector $\mathrm{c}$, so that the $\mathrm{i}$-th individual is identified as poor if $c_{i} \geq k$.

$$
\begin{array}{lll}
\rho_{k}\left(y_{i} ; z\right)=1 & \text { if } & c_{i} \geq k \\
\rho_{k}\left(y_{i} ; z\right)=0 & \text { if } & c_{i}<k
\end{array}
$$

Alkire and Foster (2011a,b) refer to the former as a dual cut-off identification method, since it combines the use of within dimensional deprivation cut-offs $z$ first, to decide whether a person is deprived or not in a given dimension, and a poverty cut-off then to determine who is deemed to suffer multidimensional poverty. It is straightforward to see that the value of $k$ will determine if a union, an intersection or an intermediate approach is used to identify the poor. 
Once identified the poor for a given cut-off, the aggregation step is based on the concept of the censored deprivation matrix $g^{0}(k)=\left[g_{i j}^{0}(k)\right]$, whose ij-th element is defined as follows:

$$
g_{i j}^{0}(k)=\left[\begin{array}{ccc}
g_{i j}^{0} & \text { if } & \rho_{k}\left(y_{i} ; z\right)=1 \\
0 & \text { if } & \rho_{k}\left(y_{i} ; z\right)=0
\end{array}\right.
$$

As Alkire and Foster emphasize, this step is key to the A-F methodology, since the censored deprivation matrices are the basic constructs used in the aggregation stage. It should also be noted that, unless a value of $k$ leading to an identification union approach is used, the construction of $\mathrm{g}^{0}(\mathrm{k})$ involves discarding information on the deprivations of the non-poor, which are thus not allowed to affect the value of the overall poverty index (i.e. the index is focused only on the situation of the poor, so accomplishing the poverty focus axiom).

If the dimensions are measured through variables which are cardinally significant, then a similarly constructed censored normalized gap matrix $g^{1}(k)=\left[g_{i j}^{1}(k)\right]$ and a censored squared gap matrix $\mathrm{g}^{2}(\mathrm{k})=\left[\mathrm{g}_{\mathrm{ij}}^{2}(\mathrm{k})\right]$ can be obtained by substituting the positive elements of $\mathrm{g}^{0}(\mathrm{k})$ for the (squared) normalized gap of each poor person in each deprived dimension. This is defined, as in the unidimensional case, as the difference between the deprivation cut-off $\mathbf{z}_{\mathbf{j}}$ and the person's achievement in each deprived dimension $\mathbf{y}_{\mathrm{ij}}$, $y_{i j}<z_{j}$, expressed as a proportion of the dimensional deprivation cut-off $z_{j}$.

As stated above, the A-F multidimensional poverty index is based on the standard FGT framework, thus providing a parametric class of measures $M_{\alpha}(y, z)$ that can be seen as the mean of a vector whose entries summarize at the individual level the extent of multidimensional deprivation, censored using the poverty line. The general form of the A-F adjusted FGT class of multidimensional poverty measures is hence given by:

$$
M_{\alpha}(y, z)=\mu\left(g^{\propto}(k)\right)=\frac{\sum_{i=1}^{n} \sum_{j=1}^{d} g_{i j}^{\alpha}(k)}{n d}, \text { for } \alpha \geq 0
$$


This expression equals the sum of the $\alpha$ powers of the normalized gaps of the poor, $\left[g^{\propto}(k)\right]$, divided by the highest possible value for this sum, $n d$. In comparison to the simple headcount measure, $\mathrm{H}$, the A-F family of measures satisfies a number of useful axioms including decomposability, symmetry, non-triviality, replication invariance, poverty focus, deprivation focus, weak monotonicity, dimensional monotonicity, normalisation, weak re-arrangement for $\alpha \geq 0$, monotonicity for $\alpha>0$, and weak transfer for $\alpha \geq 1$ (Alkire and Foster 2011a). Moreover, this index can be used with ordinal data, a useful property when analysing poverty and social exclusion.

For $\alpha=0$ the above expression gives rise to the Adjusted Headcount Ratio $M_{0}(y, z)$, which equals the mean of the (weighted) censored deprivation matrix

$$
M_{0}(y, z)=\mu\left(g^{0}(k)\right)=\frac{\sum_{i=1}^{n} \sum_{j=1}^{d} g_{i j}^{0}(k)}{n d}
$$

The $M_{0}(y, z)$ index shows the total weighted deprivations experienced by the poor as a proportion of all the total potential deprivations that the society could experience, and can be expressed as the product of the multidimensional headcount $\mathrm{H}(\mathrm{y}, \mathrm{z})$ and the normalized average deprivation score among the poor $\mathrm{A}(\mathrm{y}, \mathrm{z})$, where

$$
\begin{aligned}
& H(y, z)=q / n \\
& A(y, z)=\frac{1}{q d} \sum_{i} c_{i}(k)
\end{aligned}
$$

$\mathrm{H}$ represents the share of the population identified as poor (incidence), whereas A shows the average breadth or multiplicity of deprivation people suffer at the same time (intensity) ${ }^{31}$. It is worth noting that this decomposition is similar in many ways to that existing for the $F G T_{1}$ index in the unidimensional framework, as the product of $\mathrm{H}$ and the income gap ratio I.

\footnotetext{
${ }^{31}$ Foster (2013).
} 
For $\alpha=1$ we obtain the Adjusted Poverty Gap $M_{1}(y, z)$, which equals the mean of the censored normalized gap matrix $\mathrm{g}^{1}(\mathrm{k})$, and can also be expressed as the product of the adjusted headcount ratio $M_{0}(y, z)$ and the average poverty gap $G(y, z)$ across all dimensions in which poor people are deprived.

$$
\begin{aligned}
& M_{1}(y, z)=\mu\left(g^{1}(k)\right)=H A G \\
& G(y, z)=\frac{\sum_{i=1}^{n} \sum_{j=1}^{d} g_{i j}}{\sum_{i=1}^{n} \sum_{j=1}^{d} g_{i j}^{0}}
\end{aligned}
$$

The adjusted poverty gap is the sum of the normalized gaps of the poor, or $\left[g^{1}(k)\right]$, divided by the highest possible sum of normalized gaps, $n d$.

For $\alpha=2$ we obtain the adjusted FGT measure $M_{2}(y, z)$, defined as the sum of the squared normalized gaps of the poor, or $\left[g^{2}(k)\right]$, divided by the highest possible sum of the squared normalized gaps, $n d . M_{2}$ can also be expressed as the product of the adjusted headcount ratio $M_{0}$ and the average severity index $S(y, z)$, defined as the average squared poverty gap across all dimensions in which poor people are deprived.

$$
\begin{aligned}
& M_{2}(y, z)=\mu\left(g^{2}(k)\right)=H A S \\
& S(y, z)=\frac{\sum_{i=1}^{n} \sum_{j=1}^{d} g_{i j}^{2}}{\sum_{i=1}^{n} \sum_{j=1}^{d} g_{i j}^{0}}
\end{aligned}
$$

As Alkire and Apablaza (2012) show, these $\alpha>0$ measures can reflect the depth and severity of multidimensional poverty, and satisfy stronger axioms related to monotonicity and transfer. However, they cannot be easily applied when variables are not cardinally significant. In our analysis, we have relied mainly on $M_{0}$, but have also computed the $M_{1}$ index, using the normalized poverty gaps in the income and work intensity dimensions.

\section{b) Data sources}


The five European countries considered (Germany, France, the United Kingdom, Spain and Italy) account for $63 \%$ of the total EU27 population, and they are by far the countries hosting the largest numbers of non-EU27-born residents, around 25 million people in the year 2012 (7,8\% of the total population of these countries). Third-country immigrants in turn form the majority (two out of three) of the total foreign-born persons residing in these countries ${ }^{32}$. In relative terms, non-EU27 immigrants account for around $8 \%$ of the total population in UK, Germany and France, $6 \%$ in Italy, and $9 \%$ in Spain (2012 data). On the other hand, Canada is, together with Australia, New Zealand and the United States, one of the most significant and traditional immigration countries outside Europe, with a share of foreign-born residents of around 25\% (Widmaier and Dumont, 2011) and one of the highest per capita immigration rates in the world. It has been also considered for long one of the most successful countries in the field of migrant integration, which makes interesting the comparison with the selected five old and new European immigration countries.

We restrict the analysis to the population aged 59 or under. On the one hand, this helps to define more homogeneous sociodemographic groups, leaving aside migration related to non-labour reasons such as retirement. On the other hand, narrowing the scope in this way allows us to analyse a group for which the three relevant dimensions covered in the at-risk-of-poverty or social exclusion indicator are fully defined.

The data employed come from the four latest EUSILC cross-sectional waves for European countries, covering the period 2008-2011. For Canada, the 2009 wave of the Survey of Labour and Income Dynamics (SLID) is used, as it represents the most similar survey to EUSILC data, and the only one containing to date (though only for Ontario) material deprivation questions similar to those collected in EU countries. In order to obtain indicators as comparable as possible for Canada and other countries, European definitions have been applied to Canadian microdata to construct the low income and the work intensity variables. To that end, the total amount of social contributions has been deducted from the after-tax income concept included in the SLID ${ }^{33}$, while the OECD modified equivalence scale has been applied to obtain adjusted disposable income at the household

\footnotetext{
32 Eurostat, http://appsso.eurostat.ec.europa.eu/nui/show.do?dataset=migr pop3ctb\&lang=en.

33 These include the employment insurance contributions, the Canadian \& Quebec pension plan contributions and the public health insurance premiums paid off by the households. See Martínez, Alameh and Ruiz-Huerta (2014) for a more detailed description of the methodology used to obtain the new variables for Canada.
} 
level. The work intensity indicator has been computed using information regarding the total number of weeks worked during the reference period by the household members, adjusting for part-time jobs and excluding students aged 18-24 and all people over 60 years old, as in Eurostat statistics. Finally, the material deprivation measure has been defined using the list of ten variables included in Ontario's Material Deprivation Index, which is not fully comparable with the EUSILC scale (see Table A.1 in the Annex). For this reason, comparisons involving material deprivation levels should be treated with caution ${ }^{34}$.

Finally, immigrants are defined in this paper as people who are foreign-born, without further differentiating between EU27 or third-country nationals for EUSILC countries $^{35}$. For Canada, the country of birth is not provided in the Public Use Microdata File, so that migrant status has to be derived from a direct question ${ }^{36}$. The answers to this question show that $17,5 \%$ of people aged 16 or more defined themselves as immigrants, while 33,7\% said they were not and almost $49 \%$ declared they did not know. Children aged 15 or under, for whom migrant status is not available, are considered to be immigrants as long as they live in a household headed by an immigrant, both in Canada and in EUSILC countries. The resulting figures for the different countries are shown in Table A.2 (see Annex).

\section{Empirical results}

\section{a) Current definition}

Graph 1 shows the average risk-of-poverty or social exclusion rates for the total population under the age of sixty, differentiating between natives and immigrants, in the six countries and Ontario, using current Europe 2020 definitions and thresholds. For Canada, these rates have been estimated by adjusting upwards the values obtained when taking into account low income and very low work intensity ratios, and then assuming the same material deprivation rate (and the same degree of overlap with the other two dimensions)

\footnotetext{
34 This issue is discussed further in Martínez, Tetoofa and Ruiz-Huerta (2014). Notten (2013) offers a recent paper which also compares in detail material deprivation indicators between Canada and some European countries, focusing on children.

35 Since this breakdown is not available in the case of Germany.

${ }^{36}$ The wording of this question is as follows: "Are you now, or have you ever been, a landed immigrant? A "landed immigrant" is a person who has been granted the right to live in Canada permanently by immigration authorities". See Statistics Canada http://www23.statcan.gc.ca/imdb-bmdi/instrument/3889 Q6 V5eng.pdf.
} 
observed in the case of Ontario. This province accounts for the largest part of the Canadian population (almost 40\%) and has economic and social indicators that can in many fields be taken as good proxies for the overall values for the country. It also hosts the largest share of immigrants residing in Canada. Using SLID-2009 data, 55\% of selfdeclared immigrants were living in this province.

According to the EU2020 indicator, France and Germany are the countries that had the lowest overall risk of poverty or exclusion, about $20 \%$, and Italy and Canada the highest, above 25\%, with Spain and the United Kingdom lying in between. As can be easily seen in Table A.3, this order is exactly the same that would emerge from using only low income rates except for Spain, which had high low income rates but scored better than in the other two domains ${ }^{37}$. If we focus on immigrants, however, there is a clear divide between Germany $(26,7 \%)$ on the one hand, and France, Italy and Spain, on the other, with rates around $38-40 \%$. Immigrants in Canada exhibit risks only slightly lower than these latter countries and a little above Ontario and the United Kingdom.

\section{Graph 1}

\section{At-risk-of-poverty or exclusion rates by migrant status, 2009}

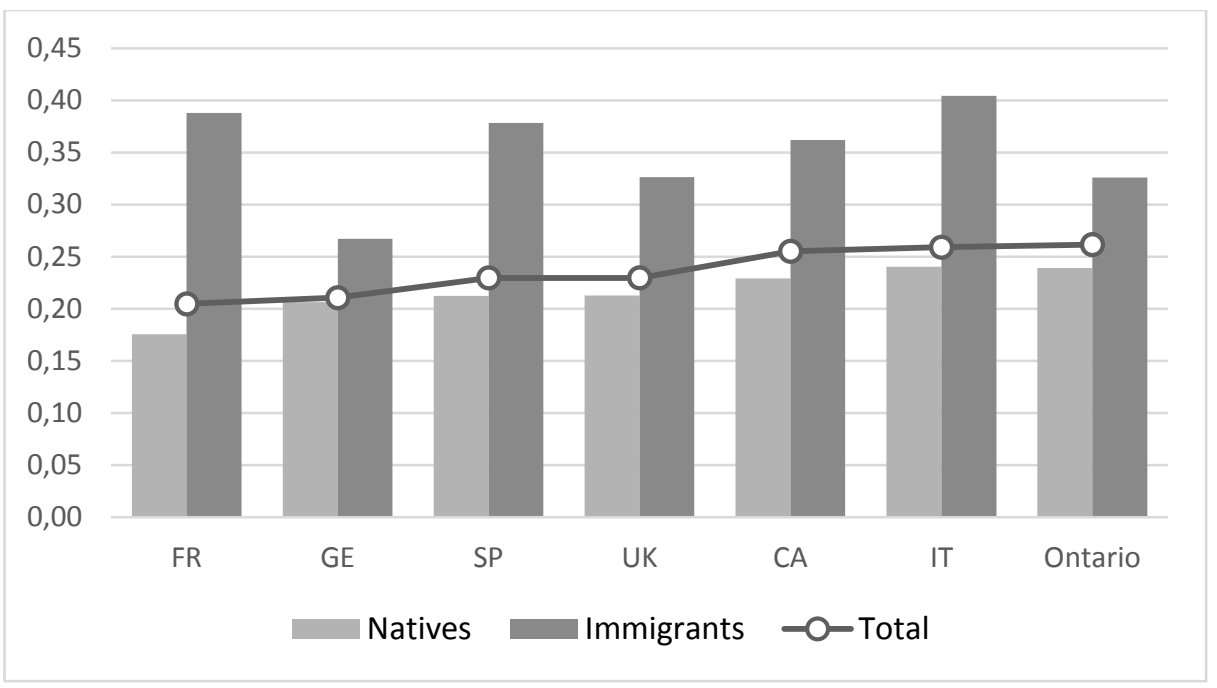

Source: Authors' elaboration, using cross-sectional 2009-SILC anonymised user database, version 01-08-2011, for European countries, and SLID-2009 Public Use Microdata File for Canada.

Graph 1 and Table A.3 also make it clear that Italy, Spain and, especially, France show the highest disparities between native and foreign-born, with poverty and exclusion

${ }^{37}$ Especially in terms of material deprivation. Many studies have highlighted this fact using different indicators; see for example recent work by Bossert et al. (2013) or De Neubourg et al. (2012). 
rates among immigrants that almost double (or more than double, in the case of France) those existing for the native-born. In contrast, differences are lowest in Germany and Ontario, particularly within prime age adults (25-59 years old $)^{38}$. As Table A.3 shows, children and young immigrants tend to score worse than adults in all countries, with the greatest impacts seen in Italy and the United Kingdom.

\section{Graph 2}

Breakdown of the at-risk-of-poverty or exclusion of immigrants, according to the number of deprived dimensions, 2009

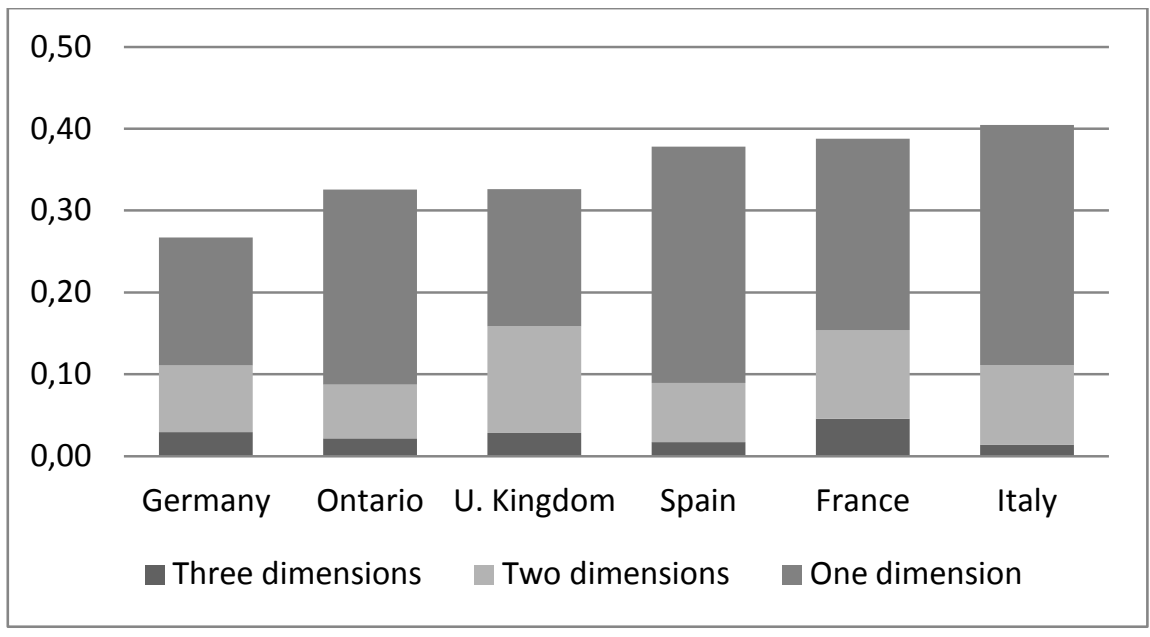

Source: Authors' elaboration, using cross-sectional 2009-SILC anonymised user database, version 01-08-2011, for European countries, and SLID-2009 Public Use Microdata File for Canada.

As previously stated, the overall poverty or exclusion rate can hide very different overlapping patterns among dimensions, thus affecting the poverty profile of the groups deemed to be at risk. Graph 2 shows that this is clearly true for 2009 data: in Ontario, Italy and Spain, more than $70 \%$ of those immigrants considered to be at risk by the Europe 2020 indicator are deprived in only one dimension (mostly income), but do not accumulate deficits in other domains, due especially to the very low prevalence of low work intensity among immigrant households in these three countries. This is much less so in the three traditional European immigrant-receiving countries, and especially in the United Kingdom, where only half of total at-risk immigrants report deprivation in only one field.

\footnotetext{
${ }^{38}$ A recent OECD report shows that the widest poverty gaps between native and foreign-born (according to the $50 \%$ of median income indicator) in 2008 were found in France, Belgium and the Nordic countries (except Sweden), see OECD (2012), p. 55.
} 
Thus, changing the union approach used to obtain the AROPE statistics to an intermediate or an intersection method to identify the poor would result in a different ranking among countries, although the numbers falling simultaneously below the three cutoffs, in their current formulation, are extremely small even for immigrants (Graph 2). Examining the overlaps would also help to clarify the different patterns of disadvantage of immigrant families, compared to native-born citizens. As explained before, this can best be done by modifying some of the choices made to build the current at-risk-of-poverty or exclusion indicator, mainly regarding the material deprivation index, and complementing the headcount ratio with the two first Alkire-Foster multidimensional poverty measures. The adjustments in the material deprivation index are intended to increase the level of consistency and comparability of the scale currently used, checking the sensitivity of results when a different list of indicators is used and also when the threshold is changed, so that not only "severe" material deprivation situations are considered to be risk-generating. At the same time, computing Alkire-Foster $\mathrm{M}_{0}$ and $\mathrm{M}_{1}$ measures will provide us with alternative summary estimates of the risk of poverty and exclusion which, unlike the headcount ratio, are able to reflect the intensity, and not only the extension, of the disadvantages suffered by households.

\section{b) Changing the material deprivation measure}

Table A.4 shows the material deprivation rates resulting from two alternative and less severe measures which can be obtained from the set of deprivation indicators currently collected in EUSILC. The first relies on the same list of nine indicators, but changes the dimensional threshold, so that households are considered deprived if they cannot afford three or more goods or activities, instead or four or more. The second also replaces the items for basic commodities which are not retained in the updated list which has been collected since 2013 (television, telephone, washing machine) with three indicators related to the difficulty of making ends meet, the affordability of dental care when needed, and the enforced lack of a computer at home. For Ontario, the three definitions correspond to applying respectively the thresholds of three or more items, two or more items (the official cut-off in Ontario's Poverty Reduction Strategy) and one or more items out of the list of 10 indicators included in the Ontario Material Deprivation Index. As the table clearly shows, Spain stands out as being the country most affected by these changes, especially among immigrants (Graph A.1). Using the third definition, almost one in two foreign-born 
persons suffered material deprivation in 2009 , as opposed to only $11,6 \%$ in the first column. Using the second concept, which gives rise to results that lie in between the two other approaches for all the countries, the material deprivation rate of Spanish immigrants would be $31,9 \%$, the highest, together with Italy, among the six countries.

Graph 3 below shows how changing the material deprivation index would affect the overall at-risk-of-poverty or exclusion rates for the immigrant population in Spain and the other countries, keeping the remaining AROPE measurement assumptions constant. Both alternatives produce a more differentiated pattern across countries, with overall rates well above $50 \%$ in Spain and Italy when the second list of indicators is used.

\section{Graph 3}

\section{At-risk-of-poverty or social exclusion rate for the immigrant population with different definitions of the material deprivation indicator, 2009}

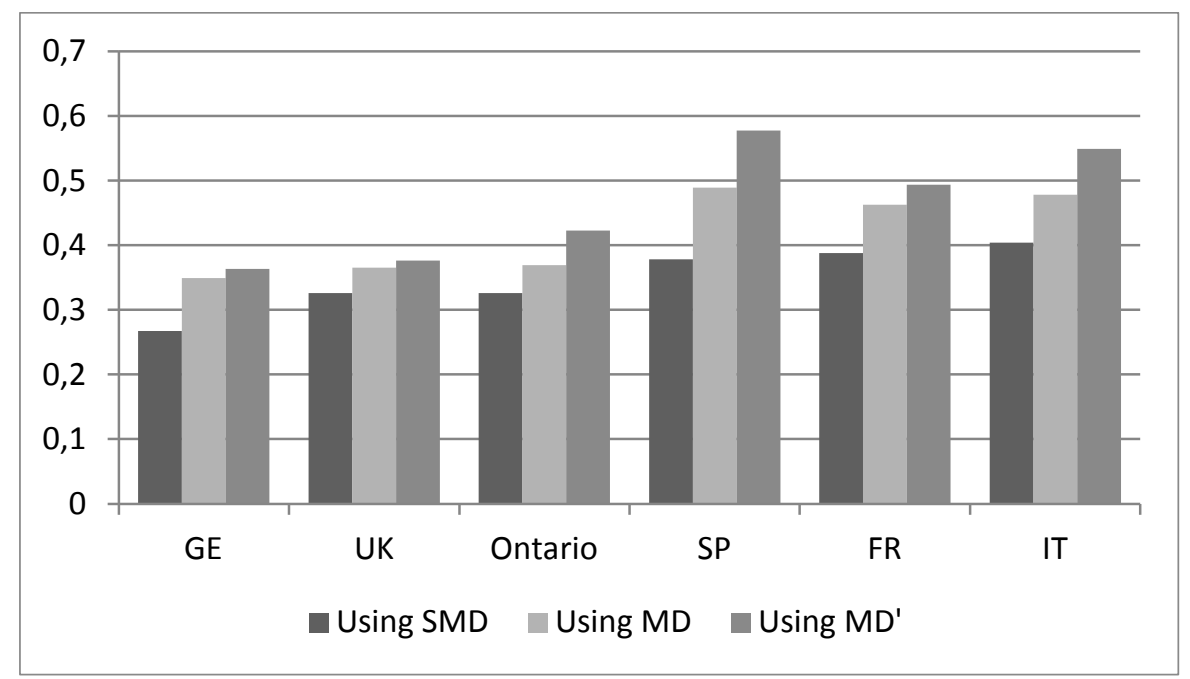

Source: Authors' elaboration using cross-sectional 2009-SILC anonymised user database, version 01-08-2011, for European countries, and SLID-2009 Public Use Microdata File for Canada.

\section{c) Computing the A-F indices}

Table A.5 displays the results obtained when computing the Alkire-Foster measures $\mathrm{M}_{0}$ and $\mathrm{M}_{1}$ for the three possible values of $\mathrm{k}$ compatible with the Europe 2020 dimensional structure. These estimates are constructed using the intermediate definition of material deprivation, giving rise to simple union headcounts ratios ranging between 0,25 and 0,31 for the whole population aged under sixty, and between 0,35 and 0,49 for the same age group who were foreign-born. To facilitate comparisons, Table A.6 shows the same ratios 
as a percentage of the mean corresponding to the five EUSILC countries. It is clear from these results that both the value of $k$ and the summary measure chosen significantly affect the ordering of the countries, for the whole population as well as among immigrants. In Ontario and the two southern European countries, the Adjusted Headcount and Poverty Gap Measures lead to significantly lower estimates of the risk of poverty and exclusion, so improving their comparative performance. This is true for the whole population as well as for the foreign-born, although it is worthwhile highlighting that, in the latter case, only the intersection approach makes a real change in Italy and Spain. On the other hand, immigrants show a worse relative position in terms of the Adjusted Headcount Ratio in Germany, the United Kingdom and, especially, France, compared to the initial AROPE ranking. In the last two countries, but not in Germany, this worsening is much greater than for the foreign-born, thereby suggesting the existence of a bigger origin-related gap at the bottom of the multidimensional poverty scale. A similar picture emerges from the use of the Adjusted Poverty Gap, also included in Table A.5.

\section{Graph 4}

\section{Relative risk of poverty or social exclusion for foreign-born population aged under 60 using different measures, 2009}

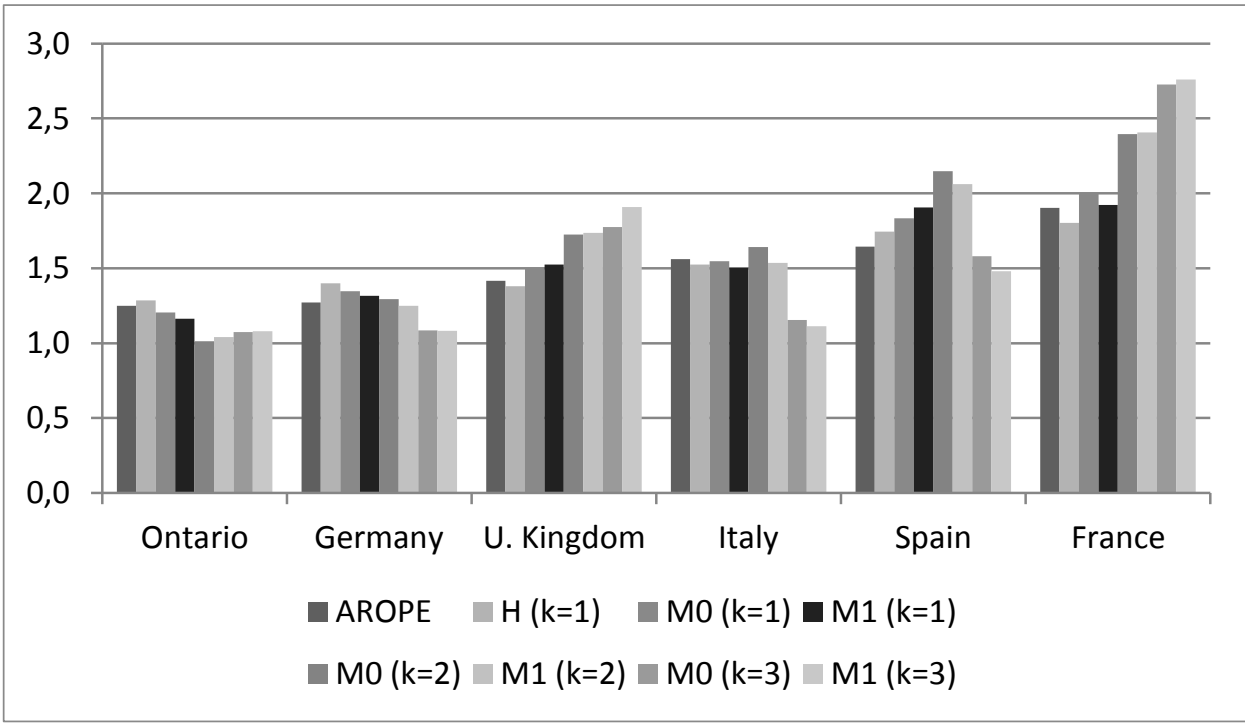

Note: The graphic shows the risk of poverty or exclusion of foreign-born population, divided by the values of the same indicator for the native born, both under 60 .

Source: Authors' elaboration, using cross-sectional 2009-SILC anonymised user database, version 01-08-2011, for European countries, and SLID-2009 Public Use Microdata File for Canada. 
The extent to which changing the multidimensional index modifies the conclusions regarding the relative position of immigrants in each country is clearly shown in Graph 4, which represents an immigrant's probability of being at-risk-of-poverty or exclusion, compared to the whole population aged under sixty, according to the original and the modified union headcount ratios (first and second bars), and to the Alkire-Foster measures for $\alpha=0$ and $\alpha=1$, under the three possible identification approaches. Some interesting facts emerge from the results above. Firstly, taking into account the degree of overlap between dimensions and the size of the gaps in the income and work intensity domains significantly increases the relative risk of the foreign-born in the United Kingdom and, especially, France, which shows by far the largest divide between immigrants and the native-born. In contrast, it decreases the relative risk in Germany and, especially, Ontario. If differences between immigrants and non-immigrants with regard to the risk of poverty and social exclusion can be taken as a proxy to the success of the integration process, this Canadian region would yield the best results, and France the worst. For Spain and Italy, the results are mixed: compared to the initial AROPE picture, the relative risk faced by the foreignborn tends to grow (Spain) or remains stable (Italy) for both $\mathrm{M}_{0}$ and $\mathrm{M}_{1}$ when using the union or the intermediate identification approach, but drops sharply for $\mathrm{k}=3$ measures. With these latter indicators, Italy would exhibit nearly non-existent gaps, like Germany and Ontario. In the case of Spain, the risk would remain well above the values of the general population, but below the levels suggested by the original union headcount measure.

On the other hand, in all countries, but especially in Spain and France, the change in the identification approach (choice of $k$ ) has far more impact upon the gap between nationals' and immigrants' risk of poverty or exclusion than the particular measure used $(\mathrm{H}$, $\mathrm{M}_{0}$ or $\mathrm{M}_{1}$ ). This result is not surprising, given the reduced number of total dimensions involved, but raises important issues regarding the policy implications of different identification thresholds. The fact that only very few immigrant households had in 2009 low work intensity in some of these countries contributes significantly to the decline in risk rates when employing an intersection approach, and can obviously be construed as indicating a good degree of integration in the labour market. However, this pattern also has a disturbing reading, since it means that jobs and high work intensity are not necessarily enough to lift many immigrants out of poverty and material deprivation. Moreover, as many studies have emphasized, the labour integration of migrants has been comparatively 
high, but also extremely precarious, in Spain and some of the other Mediterranean countries in which immigration is a new phenomenon ${ }^{39}$.

\section{d) Dimensional breakdown}

As explained before, the A-F measures are additively decomposable by groups and, after identification, by dimensions too. The dimensional breakdown can be useful to show how different domains or indicators contribute to overall poverty, in the whole population or in a given subgroup. Following Alkire and Foster (2011a,b), the contribution of dimension $j$ to the Adjusted Headcount Ratio $\left(\mathrm{M}_{0}\right)$ can be calculated as:

$$
c_{j}=\frac{\left(w_{j} / d\right) H_{j}^{C}}{M_{0}}
$$

Where $H_{j}^{C}$ is the censored Headcount Ratio showing the proportion of people who are both poor $\left(\rho_{k}\left(y_{i} ; z\right)=1\right)$ and deprived in a given dimension or indicator $j\left(y_{i j}<z_{j}\right)$ :

$$
H_{j}^{C}=\frac{\sum_{i=1}^{n} g_{i j}^{0}(k)}{w_{j} n}
$$

Note that for $\mathrm{k}=1$ (union approach) there is no difference between the censored and the raw headcount ratios. On the other hand, for $\mathrm{k}=\mathrm{d}$ (intersection approach), the relative contribution of each dimension necessarily equals its weight, since by definition only those simultaneously deprived in all areas are considered poor.

Graph A.2 displays the censored headcount ratios by dimension in 2009 for immigrant and native-born population aged under 60, using a union $(\mathrm{k}=1)$ and an intermediate $(k=2)$ identification approach. Graphs A.3 and A.4 show in turn the dimensional breakdown of $\mathrm{M}_{0}$ in each country, for $\mathrm{k}=1$ and $\mathrm{k}=2$. An important conclusion that can be drawn from this analysis is that low work intensity contributes relatively less to

\footnotetext{
${ }^{39}$ See among others Alcobendas and Rodríguez (2009), Amuedo-Dorantes and De la Rica (2009, 2007), Aysa and Cachón (2013), Cachón (2009), Calderón and Hidalgo (2007), Canal-Domínguez and RodríguezGutiérrez (2008), Caparrós and Navarro (2010), Cebolla-Boado y González-Ferrer (2013), Fernández and Ortega (2008), Gradín and Del Río (2013), Izquierdo et al (2009), Martín et al. (2011), Pérez-Infante (2009), Simón et al. (2011, 2008). Although integration in the labour market is by far the most researched aspect in Spain, there are also some papers specifically focused on poverty among immigrants, see among others Martínez (2010) or Muñoz de Bustillo and Antón (2011).
} 
overall poverty among immigrants that among native-born population, for both values of $\mathrm{k}$. This is especially true in Spain and Italy, where the percentage of total immigrant poverty stemming from employment deprivation was around half or less the values obtained for the native-born. It also fits quite well the Canadian case when using the union, but not the intermediate, identification approach. The comparatively high values of the Adjusted Headcount Ratios for immigrants in the two South-European countries are mainly due to the high incidence of low income and, especially, material deprivation among immigrant families, even when working full time. Both dimensions taken together contribute to overall immigrant poverty well above their weight, explaining at least $90 \%$ of total poverty for $\mathrm{k}=1$, and around $85 \%$ for $\mathrm{k}=2$.

For the rest of the countries, the relative contribution of each dimension to overall poverty among immigrants is much closer to that observed for the native-born, although there are huge differences in absolute values between the two groups (especially in France and the United Kingdom). Germany and, especially, Ontario exhibit the lowest gaps between the two groups, as stated before, but the structure of multidimensional poverty differs in the two countries when using the union approach: low income contributes more to immigrant poverty in Ontario than in Germany, and the opposite is true for material deprivation and low work intensity.

\section{e) Changes during the economic downturn}

The current economic recession has placed the social agenda in some European countries under pressure, due to stagnating real income, rising unemployment and higher low-income rates among the working age population in many countries. Spain stands out in this context as one of the countries in which the overall risk of poverty and social exclusion has increased most markedly since the mid-00s, from around $24 \%$ during the period 2005 2009 to 28\% in 2011 and 2012. Generally speaking, this deterioration has been more severe for active age adults than for retired people, due to the negative impact of the recession on the employment rates in most countries.

Graph A.5 (see Annex) shows that this is particularly the case in Spain, with a clear upsurge in low income, low work intensity and at-risk-of-poverty or exclusion rates both among native and foreign prime age adults. Severe material deprivation has also tended to 
increase, although maintaining low absolute values, due partly to the heavy weight attached to widely-owned durables in the current 9-item Eurostat list.

Graph 5 below shows the absolute change in the unadjusted headcount ratio $(\mathrm{H})$ and the A-F measures $\mathrm{M}_{0}$ and $\mathrm{M}_{1}$ (for $\mathrm{k}=1,2$ and 3) between 2009 and 2011, in the five European countries included in the analysis. It is clear from these results that Spain and, to a lesser extent, Italy, are the countries in which immigrants have suffered the highest increases in the risk of poverty and social exclusion since the beginning of the crisis, for any value of k. In contrast, changes have been much smaller in Germany, France and the United Kingdom (with $\mathrm{M}_{0}$ and $\mathrm{M}_{1}$ measures even showing a decrease among immigrants in this last country).

\section{Graph 5}

Absolute changes in $\mathrm{H}, \mathrm{M}_{0}$ and $\mathrm{M}_{1}$ measures between 2008 and 2011

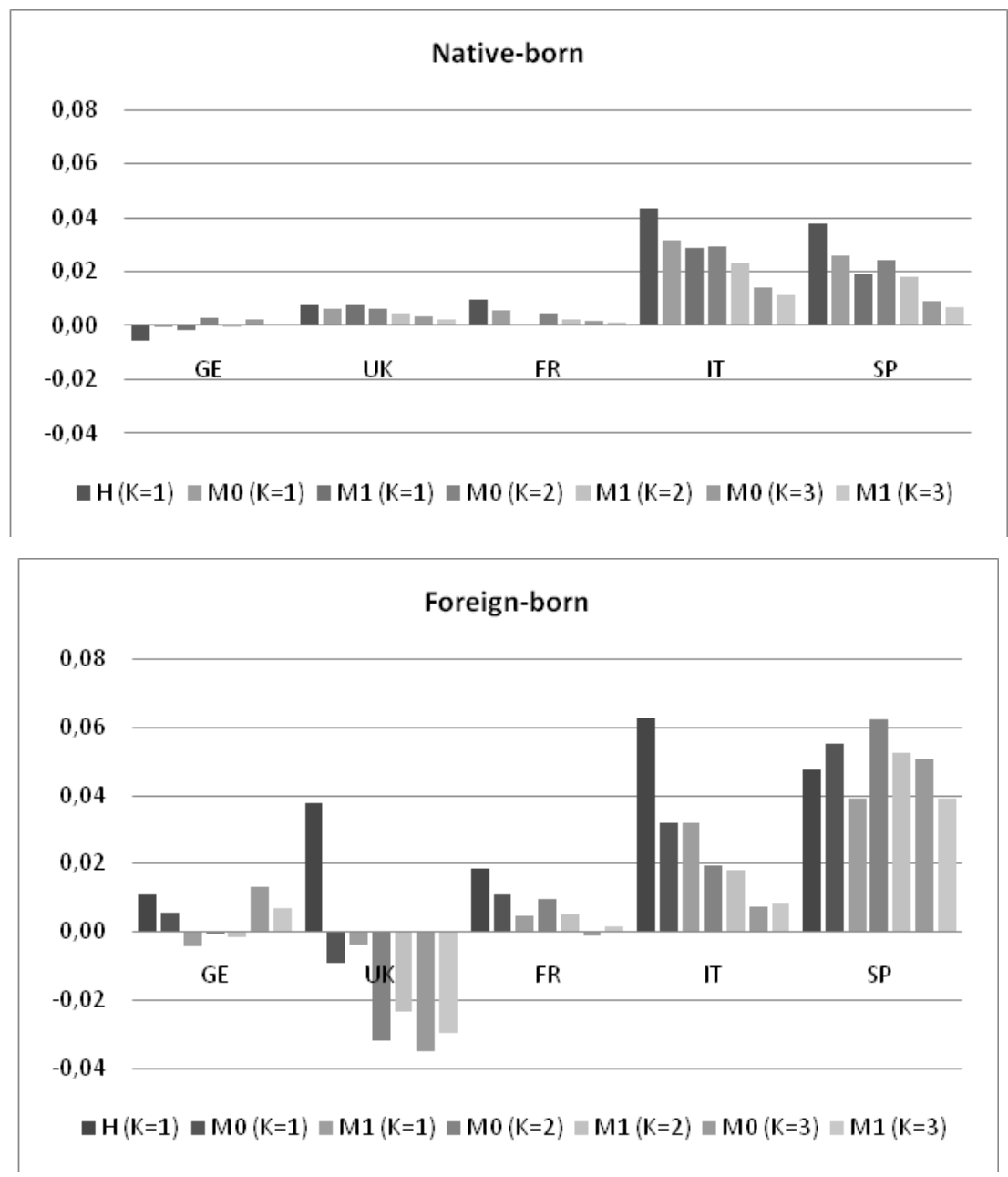

Source: Authors' elaboration, using cross-sectional 2009 and 2011 SILC anonymised user databases, versions 01-08-2011 and 01-03-13 respectively. 
How these changes have affected the risk of poverty or exclusion gap between the native and foreign-born populations can be assessed by looking at Graph 6, which displays the same set of measures contained in Graph 4 for Spain and the other four EUSILC countries, updated to 2011. The graph clearly shows to what extent the worsening of the low work intensity indicator following the onset of the economic downturn has changed the multidimensional poverty profile of immigrants in Spain, compared to other countries. In only two years, work intensity decreased sharply among immigrant households, due to rising unemployment.

\section{Graph 6 \\ Relative risk of poverty or social exclusion for the foreign-born population aged under 60 using different measures, 2011}

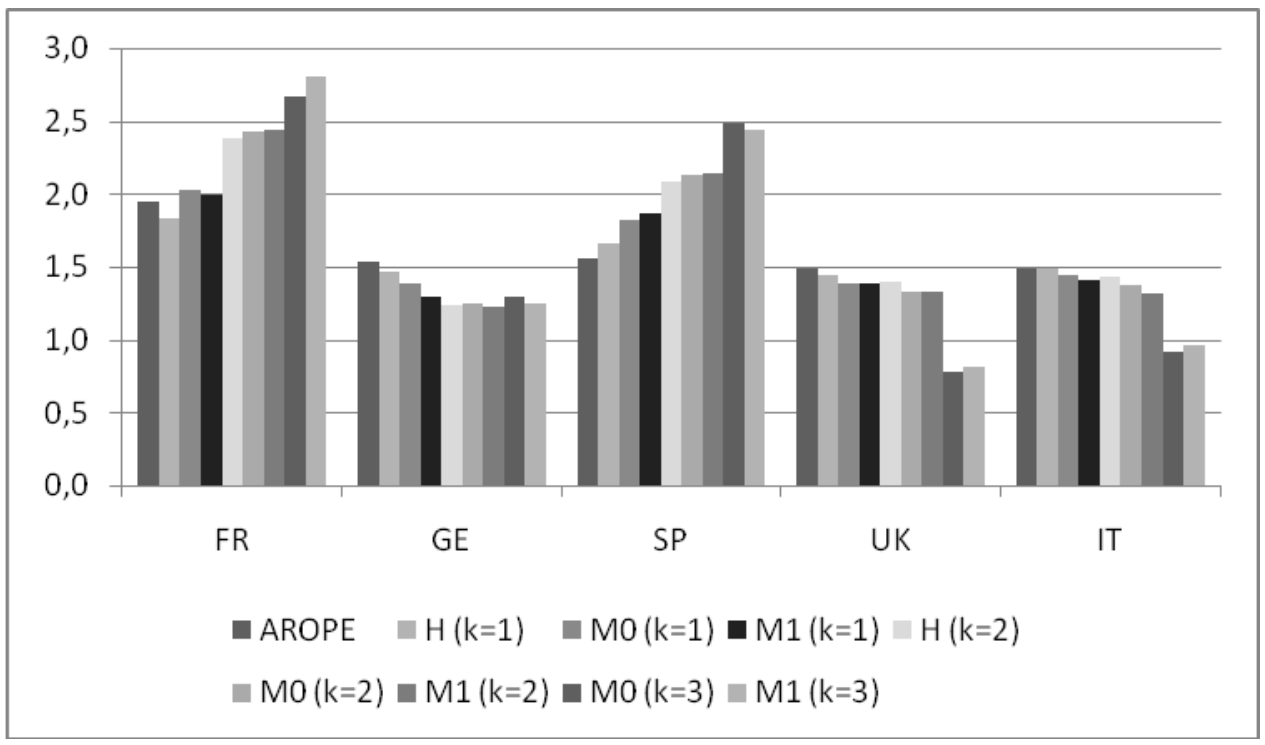

Note: The graphie shows the risk of poverty or exclusion of the foreign-born population divided by the values of the same indicator for the native-born population, both under 60 .

Source: Authors' elaboration, using cross-sectional 2009 and 2011 SILC anonymised user databases, versions 01-08-2011 and 01-03-13 respectively.

According to the Labour Force Survey data, the unemployment rate of the foreignborn population increased from around $12 \%$ in 2007 to $21 \%$ at the end of 2008 and to $32 \%$ at the beginning of 2011 . Following a transitory stabilisation in 2011, the foreign-born unemployment rate continued to rise until at least the first trimester of 2013, when it reached a striking 39\% (42\% among those born outside the EU). This deterioration was 
not only larger than that suffered by native workers, but it also had very different implications in terms of the risk of poverty and social exclusion. Many immigrant families were already receiving low incomes and/or suffering material deprivation when the economic cycle was at its peak in 2007, bur nevertheless were in work. Since the start of the economic crisis, the deprived-in-all-dimensions group has risen at a higher rate among the foreign-born, thus intensifying their risk of poverty and exclusion and widening the originrelated gap. It results in a picture in which, as in France, the position of immigrant compared to native families deteriorates as the value of $\mathrm{k}$ grows from 1 to 3 (Graph 6).

The Europe 2020 indicator has the advantage of simultaneously taking into account these three basic domains (income, employment and material living conditions) to evaluate the risk of poverty. Yet the analysis above suggests that this measure may not be sufficient to reflect the growing intensity of multidimensional deprivation in some groups or countries. This seems to be precisely the case in Spain when evaluating the impact of the beginning of the crisis on the situation of immigrant households. A decomposition of changes in the $\mathrm{M}_{0}$ measure throughout the period 2009-2011, for the intermediate identification approach $(\mathrm{k}=2)$, reveals that $18 \%$ of the increase in the value of the Adjusted Headcount Ratio for immigrants in Spain can be attributed to the "intensity of poverty" effect, compared to only a $2 \%$ for the native-born. In Italy, the other country showing significant (but lower) increases in the at-risk-of-poverty or exclusion rates during the period, this contribution amounted to $6 \%$, for both native and foreign-born individuals (see Table A.8 in Annex).

Table A.9 shows in more detail how the three dimensions and the overall summary measures have evolved in Spain throughout the period 2008-2011, for the entire population under 60 and for immigrants, broken down between prime-age adults (25-59 years old) and the youngest (0-24 years old) in the latter case. The ratio in the final column indicates the proportional change between the first and the last years considered. This table clearly confirms that work intensity is by far the dimension which most contributed to the worsening risk of poverty and exclusion, with values that have almost doubled in only three years. As explained above, this indicator has deteriorated to a greater extent for the immigrant population, whose very low work intensity rates have risen from below $4 \%$ in 2008 to above $17 \%$ in 2011. 
The data in Table A.9 also make it clear that the recession's impact on the risk of poverty and exclusion is higher when using the Adjusted Headcount Ratio and the Adjusted Poverty Gap, especially for immigrants. According to the Europe 2020 indicator, the overall poverty or exclusion rate has risen by about 30\% for the total population aged under $60(20 \%$ ?? in the case of immigrants). By contrast, this increase would amount to $40 \%$ to $150 \%$ for the A-F measures, with growing impacts as the value of $\mathrm{k}$ changes from 1 to 3 .

It should be highlighted that the rise of the $\mathrm{M}_{0}$ and $\mathrm{M}_{1}$ indices in Spain has been huge for $\mathrm{k}=3$ measures, especially among children and young people under 25 in immigrant households (Table A.9). For this group, the percentages simultaneously suffering low income, material deprivation and very low work intensity is eight times higher in 2011 than in 2008. According to the latest available data, almost $10 \%$ of immigrant children live in households deprived in all three dimensions, compared to a value of 3\% (not shown in the Table) for children in households with native-born heads. This growing gap, if not corrected, could seriously undermine not only current but also the future integration of migrant minorities in Spain, given the strong influence, widely suggested in the literature, of children's economic well-being on adult outcomes.

\section{Summary and conclusions}

1. The new multidimensional index launched by the European Strategy 2020 in 2010, as the vehicle to monitor progress in combating poverty (AROPE), represented a progress towards a multidimensional perspective of poverty, one more consistent with the social inclusion policy approach prevalent in the EU. The choice of three dimensions seems to be coherent if we consider the new index as an adaptation of the traditional risk of poverty indicator, which tries to adjust the poverty concept to the wider notion of social exclusion, while avoiding the "explosion of concern" of many indiscriminate listings of problems, as Sen has warned against.

2. The use of income and deprivation indicators would confirm the trend, increasing over the last decade, towards combining the two approaches when analysing poverty. On the other hand, the introduction of the work intensity dimension contributes to giving political priority to the unemployment problem, so reinforcing the shared view that jobs are crucial 
to minimize the risk of poverty and make social inclusion easier. It also allows policymakers to identify those households which, despite suffering neither low income nor material deprivation at present (because they are receiving temporary transfers or are relying on savings), do in fact have a problem of lack of economic autonomy and marked vulnerability to poverty and social exclusion, if the low work intensity situation persists.

3. The three dimensions considered are also especially useful to study immigrant integration. Employment is in fact regarded as a key part of integration in EU countries. On the other hand, although the integration of immigrants is a long-term process involving other aspects that go beyond income and jobs, the ability to avoid poverty and achieve a minimum standard of living is vital for integration in the remaining domains.

4. Nevertheless, the definition used by the EU has some shortcomings, which must be highlighted. Firstly, as discussed in the paper, the indicators and thresholds used to represent deprivation in each domain may not be the best choice for all countries, due especially to the combination of relative national income standards with EU-wide common material deprivation indicators. For longstanding EU members, the abovementioned definition results in large groups who live on low incomes but do not report severe material deprivation (and the opposite is true for many of the poorer new member countries). Secondly, the identification method used when constructing the "at-risk-of-poverty or social exclusion" indicator is based on a unified approach, thereby ignoring differences in the degree of overlap among the three dimensions. Thirdly, the Europe 2020 poverty indicator provides a simple headcount measure, which is sensitive neither to the number of deprived dimensions of those identified as poor nor to the size of the gaps within each domain.

5. These limitations imply that there is room to supplement or adapt the new basic indicator, in order to gain insight when analysing vulnerability to poverty and social exclusion in a particular subset of European Union countries. A productive way to do so may be to insert the Europe 2020 indicator into a more general class of multidimensional poverty indices, flexible enough to permit the robustness of conclusions to be checked when a set of basic parameters are modified. In our view, the Alkire-Foster family of measures provides the most suitable approach to support this generalisation within the Europe 2020 framework. Although other interesting multidimensional poverty measures 
exist in the literature, the A-F indices have certain properties, which make them a good choice to analyse poverty and social exclusion in the European context.

6. The empirical part of this paper analyses multidimensional poverty profiles of immigrant households in Spain and a further five developed countries, using both the standard Europe 2020 approach and the A-F methodology. According to the original EU2020 indicator, France and Germany are the countries having the lowest overall risk of poverty or exclusion (approximately 20\%), and Italy and Canada the highest, above 25\%, with Spain and the United Kingdom lying in between. If we focus on immigrants, however, there is a clear difference between Germany (26.7\%) on the one hand, and France, Italy and Spain, on the other, with rates of around 38-40\%. Immigrants in Canada suffer risks only slightly lower than these latter countries and slightly above Ontario and the United Kingdom.

7. Using the Alkire-Foster measures $\mathrm{M}_{0}$ and $\mathrm{M}_{1}$ for the three possible values of $\mathrm{k}$ compatible with the Europe 2020, the dimensional structure changes the comparative performance of immigrants in some countries. On the one hand, when the degree of overlap among dimensions and the size of the gaps in the income and work intensity domains are taken into account, these significantly increase the relative risk of the foreignborn in the United Kingdom and, especially, France. By contrast, such considerations decrease the relative risk in Germany and Ontario. For Spain and Italy, the results are mixed: compared to the initial AROPE picture, the relative risk faced by the foreign-born tends to grow (Spain) or remains stable (Italy) when using the union??? or the intermediate identification approach, but drops sharply in the case of the intersection measures. Italy, Spain and, most markedly, France showed in 2009 the highest disparities between native and immigrants, with poverty and exclusion rates among immigrants that almost double (or more than double, in the case of France) those existing for the native-born.

8. The dimensional decomposition of $\mathrm{M}_{0}$ shows that the comparatively high values of the Adjusted Headcount Ratios for immigrants in Italy and Spain are mainly due to the high incidence of low income and, especially, material deprivation among immigrant families, even when working full time. Both dimensions taken together contribute to overall immigrant poverty well above their weight, explaining at least $90 \%$ of total poverty for $\mathrm{k}=1$, and around $85 \%$ for $\mathrm{k}=2$. The fact that only very few immigrant households had low 
work intensity in 2009 in some of these countries contributes significantly to the decline in risk rates when employing an intersection approach, but also means that jobs and high work intensity are not always sufficient to lift immigrants out of poverty and material deprivation.

9. As many studies have emphasised, the labour integration of migrants has been comparatively high, but also extremely precarious, in Spain and other new European immigration countries. The current economic recession has sharply worsened the employment position of the foreign-born in many countries. Our analysis clearly shows that Spain, and, to a lesser extent, Italy, are the countries where immigrants have suffered the highest increases in the risk of poverty and social exclusion since the beginning of the crisis (among the five large European countries compared in this paper), for any value of $\mathrm{k}$. The decomposition of changes in the $\mathrm{M}_{0}(\mathrm{k}=2)$ measure into "incidence" and "intensity" effects uncovers a higher than average role of the intensity component in Spain for the foreign-born population. In fact, the number of immigrant families suffering simultaneously low income, material deprivation and very low work intensity is six times higher in 2011 than in 2008. The increase has been even more noticeable for households with children, a trend that casts a shadow over current integration opportunities for migrant workers and their offspring. This change is not adequately reflected through the new Europe 2020 indicator, but becomes evident when using A-F measures sensible to the degree of overlap among dimensions.

\section{Limitations and ways forward}

To finish, it would be useful to comment upon a number of limitations of our paper and some possible solutions.

First of all, the definition of "immigrant" used in the current research is most probably too simple to account for the experiences of different subgroups within the foreign-born population, apart from being based on different criteria in Canada and the remaining countries. This problem could be partly overcome in the near future, depending on the breakdowns and definitions available in the new waves of the relevant datasets. 
Secondly, the definition of each of the three dimensions currently comprising the Europe 2020 principal indicator could be improved in several ways deserving of further research. Material deprivation indicators are now routinely included in EUSILC surveys, and much more is known about their performance and potential biases in the analysis of poverty. As a result, a new 13-items material deprivation scale has been adopted from 2013 onwards, in an attempt to solve some of the problems inherent in the old 9-items scale. But apart from improving the individual indicators used, research into material deprivation within the Europe 2020 framework could be extended in at least two directions. On the one hand, by exploring alternative weighting and aggregation schemes so that the position of a given individual on the material deprivation scale could be measured not only by the number of items she/he lacks, making it feasible to quantify the amount of the material deprivation gaps. On the other, it would be interesting to promote comparative research into material living conditions with non-EUSILC countries, taking advantage of the new material hardship data collected in other OECD countries.

In the case of low income, important efforts have already been made to increase both reliability and comparability within the EU-countries, but a number of key issues remain unsolved. The question of which is the most relevant reference group has become crucial in the context of the enlarged EU, and the same is true for the issue of how nonincome resources, such as imputed housing rent, influence the way in which low income becomes material deprivation. Neither of these aspects has been addressed in this paper, but both deserve close attention.

Furthermore, the new low work intensity definition improves to some extent the old jobless household Euro-indicator, but could be further refined to better capture the economic insecurity derived from the labour market status of household members (apart from being extended to the entire population).

Thirdly, this paper has taken for granted the dimensional structure of the main Europe 2020 poverty indicator, but it would be interesting to discuss new dimensions, relevant either to the whole population or to the analysis of particular groups, such us migrant households. In fact, the advantages of using A-F type measures instead of a simple unadjusted headcount approach are greater when applying a truly multidimensional approach, in which a number of distinctive domains are taken into consideration. In this 
context, much more research should be devoted to reinforcing the bridge between multidimensional poverty measures and the widening literature on common indicators of migrant integration in advanced countries.

Fourthly, this research has been based on cross-sectional data from surveys with a rotating panel structure, both in European SILC and Canadian SLID cases. One of the advantages of combining income, material deprivation and labour variables when identifying those at risk is probably the ability to capture, at least in part, long-term processes not fully reflected in current income. Yet the availability of repeated observations over a four-year period for each individual permits direct scrutiny of certain common assumptions regarding the dynamic relationships between employment status, income and material deprivation. Such research might in turn shed light on the best way to build a multidimensional risk of poverty index based on these dimensions.

Finally, a natural extension of the comparative work initiated by this paper would be to explore which factors can best account for the different multidimensional poverty profiles of immigrants in Spain and the other countries selected. This would require controlling for observed and unobserved heterogeneity among immigrants in the selected countries, a difficult task given the lack of some key variables in EUSILC data (for example, data on years of residence in the country is available only from 2011 onwards for all EUSILC countries). As Arango (2012) has pointed out, there are a number of reasons why immigrant integration outcomes are expected to differ between early starters and latecomers immigration countries, thus suggesting the need to disentangle the relative role of "age" and "generation" effects (linked to the context in which countries started receiving immigration) from other structural differences related to socioeconomic or migration regimes.

\section{References}

Alcobendas, M., Rodríguez, N. (2009), “Immigrants' Assimilation Process in a Segmented Labor Market”. IZA Discussion Paper 4394.

Aleksynka, M., Algan, Y. (2010), “Assimilation and Integration of Immigrants in Europe”, IZA Discussion Paper No 5185, Institute for the Study of Labour, Bonn.

Alkire, S., Apablaza, M. (2012), "Multidimensional poverty measurement for EU-SILC countries", Paper presented at the2012 EU-SILC International Conference, Vienna, 6-7 December 2012. 
Alkire, S., Roche, J.M., Seth, S. (2011), "Sub-national disparities and inter-temporal evolution of multidimensional poverty across developing countries", OPHI Working Papers.

Alkire, S., Foster, J. (2011a), "Counting and Multidimensional Poverty", Journal of Public Economics, 95: 476-487.

Alkire, S., Foster, J. (2011b), "Understandings and misunderstandings of multidimensional poverty measurement", Journal of Economic Inequality, 9, 289-314.

Alkire, S., Santos. E.M. (2010), "Acute Multidimensional Poverty: A New Index for Developing Countries”. OPHI Working Paper 38, July 2010.

Amuedo-Dorantes, C., de la Rica, S. (2009), "Complements or Substitutes? Task Specialization by Gender and Nativity in Spain", IZA Discussion Paper 4348.

Amuedo-Dorantes, C., de la Rica, S. (2007), "Labour Market Assimilation of Recent Immigrants in Spain”, British Journal of Industrial Relations, 45(2), pp. 257-284.

Angoitia, M., Tobes, P. (2013): “CCómo afecta la crisis económica a la población inmigrante?”, X Jornadas de Economía Laboral, Madrid, 11-12 July 2013.

Arango, J. (2012), "Early starters and latecomers. Comparing countries of immigration and immigration regimes in Europe", in Okolski, M. [ed.], European Immigrations. Trends, Structures and Policy Implications, 45-64, Amsterdam: Amsterdam University Press.

Atkinson, A.B., Marlier, E. (2010), “Analysing and Measuring Social Inclusion in a Global Context”, New York: United Nations.

Atkinson, A.B., Marlier, E. [eds.] (2010), Income and living conditions in Europe. Luxembourg: Publications Office of the European Union, 2010.

Atkinson, A.B. (2003), "Multidimensional Deprivation: Contrasting Social Welfare and Counting Approaches", Journal of Economic Inequality, 1, 51--65.

Ayala, L., Cantó, O., Rodríguez, J.G. (2011), "Poverty and the business cycle: The role of intra-household distribution of unemployment”, ECINEQ Working Paper No. 222, 2011.

Aysa-Lastra, M., Cachón, L. (2013), "Movilidad ocupacional segmentada: el caso de los inmigrantes no comunitarios en España", Revista Española de Investigaciones Sociológicas, 144, 23-47.

Bhalla, A.S., McCormick, P. (2009) Poverty among Immigrant Children in Europe, Houndsmills: Palgrave, McMillan.

Berthoud, R., Bryan, M. (2010), "Income, deprivation and poverty: a longitudinal analysis", Journal of Social Policy, 40(1), 135-156.

Bibi, S. (2005), "Measuring Poverty in a Multidimensional Perspective: A Review of Literature", PMMA Working Papers 2005-07. 
Borjas, G.J. (1985), Assimilation, Changes in Cohort Quality, and the Earnings of Immigrants, Journal of Labour Economics, No. 3(4), pp. 463-89.

Borjas, G.J. (2006), "Making It in America: Social Mobility in the Immigrant Population", National Bureau of Economic Research Working Papers, no 12088.

Bossert, W., Chakravarty, S.R., D'Ambrosio, C. (2013), "Multidimensional poverty and material deprivation with discrete data", Review of Income and Wealth, 59(1), pp. 29-43.

Bossert, W., Chakravarty, S.R., D'Ambrosio, C. (2009), "Measuring Multidimensional Poverty: the Generalized Counting Approach”, ECINEQ Working Papers, 2009.

Boubtane, E., Coulibaly, D., Rault, C. (2011), "Immigration, unemployment and growth in the host country: Bootstrap Panel Granger Causality Analysis on OECD countries", IZA Discussion Paper 5853.

Bourguignon, F., Chakravarty, S.R. (2003), "The measurement of multidimensional poverty". Journal of Economic Inequality. (p. 25-49)

Büchel, F., Frick, J. (2005), "Immigrants' economic performance across Europe -does immigration policy matter?”, Population Research and Policy Review, 24(2), pp. 175-212.

Burstein, M. (2005), "Combating the Social Exclusion of At-Risk Groups", Research Paper, November 2005, Ottawa: Policy Research Initiative (PRI).

Cachón, L. (2007), "La inmigración y el mercado de trabajo en la Unión Europea", Cuadernos Europeos de Deusto, No. 36/2007, pp. 77-106.

Cachón, L. (2009), La "España inmigrante": marco discriminatorio, mercado de trabajo y políticas de integración, Barcelona: Anthropos.

Calderón, M.J., Hidalgo, A. (2007), "La segregación sectorial y ocupacional de los inmigrantes en España: Identificación de los espacios laborales prioritarios en los países de origen”, VII Jornadas de Economía Laboral, 12-13 julio 2007, Las Palmas de Gran Canaria.

Canal-Domínguez, J.F., Rodríguez-Gutiérrez, C. (2008), "Analysis of wage differences between native and immigrant workers in Spain", Spanish Economic Review, 10(2), 109-134

Caparrós, A., Navarro, M.L. (2010), "Movilidad ocupacional de los inmigrantes en España", Investigaciones de Economía de la Educación, 5: 873-890.

Carrasco, C., García Serrano, C. (2012), Inmigración y mercado de trabajo. Informe 2011, Madrid: Ministerio de Empleo y Seguridad Social.

Carrasco, R., García Pérez, J.I. (2008), "Unemployment duration among immigrants and natives: unobserved heterogeneity in a multi-spell duration model," Economics Working Papers, WP 08-69, Economic Series (33), Universidad Carlos III, Madrid.

Causa, O., Jean, S. (2007), "Integration of Immigrants in OECD Countries: Do Policies Matter?", OECD Economics Department Working Papers, No. 564, OECD Publishing. 
Cebolla-Boado, H., González-Ferrer, A. (2013), Inmigración, zintegración sin modelo?, Madrid: Alianza Editorial.

Chiswick, B.R. (1978), The Effect of Americanization on the Earnings of Foreign-born Men, Journal of Political Economy, No. 86(5), pp. 897-921.

de Giorgi, G., Pellizzari, M. (2009). 'Welfare migration in Europe', Labour Economics, 16(4), 353-363.

de Neubourg, C., Bradshaw, J., Chzhen, Y., Main, G., Martorano, B., Menchini, L. (2012), "Child deprivation, multidimensional poverty and monetary poverty in Europe", UNICEF Innocenti Working Paper 2012/02, Background paper 2 for UNICEF Innocenti Report Card 10.

Deutsch, J., Silber, J. (2006), "Ethnic origin and multidimensional relative poverty in Israel: a study based on the 1995 Israeli census", Research in Labour Economics, 24, 235-264.

Dickes P., Fusco A., Marlier, E. (2008), "Socially perceived necessities of life across EU countries: Structures and consensus", Paper presented at the 30th IARIW General Conference, Slovenia, 24-30 August.

Duclos, J.Y., Sahn, D., Younger, S.D. (2006), "Robust Multidimensional Poverty Comparisons with Discrete Indicators of Well-being”, CIRPÉE Working Paper, 06-28.

European Commission (2010a), Handbook on Integration for policy-makers and practitioners, $3^{\text {rd }}$ edition, April 2010, Directorate-General for Justice, Freedom and Security, European Communities, Brussels 2010.

European Commission (2010b), "Europe 2020. A strategy for smart, sustainable and inclusive growth", Communication from the Commission, COM (2010) 2020 final, Brussels, 3.3.2010.

European Commission (2007), Handbook on Integration for Policy-Makers and Practitioners, 2nd ed., Directorate-General for Justice, Freedom and Security, European Communities, Brussels, 2007.

Facchini, G., Mayda, A.M. (2009), 'Does the welfare state affect individual attitudes toward immigrants? Evidence across countries', Review of Economics and Statistics, 91(2), 295-314.

Fernández, C., Ortega, A.C. (2008), "Labour Market Assimilation of Immigrants in Spain: Employment at the Expense of Bad Job-Matches?", Spanish Economic Review, No. 10(2), pp. 83-107.

Fix, M.E. [ed.] (2009). Immigrants and Welfare: The impact of welfare reform on America's newcomers, New York: Russell Sage Foundation.

Fusco, A., Guio, A-C., Marlier, E. (2013), "Building a Material Deprivation Index in a Multinational Context: Lessons from the EU Experience", in V. Bérenger and F. Bresson (eds.), Poverty and Social Exclusion Around the Mediterranean Sea, Economic Studies in Inequality, Social Exclusion and Well-Being, Vol. 9. New York: Springer. 
Fusco, A, Guio, A-C., Marlier, E. (2010a), "Characterizing the income poor and the materially deprived in European Countries", in A. B. Atkinson and E. Marlier [eds.], Income and Living Conditions in Europe. Luxembourg: Publications Office of the European Union.

Fusco, A, Guio, A-C., Marlier, E.: (2010b), "Income poverty and material deprivation in European countries", Eurostat Methodologies and Working Papers, Luxembourg.

García Serrano, C., Malo, M.A. (2008), "Mercado de trabajo". In Arriba, A. (coord.), Políticas y bienes sociales. Procesos de vulnerabilidad y exclusión social. Madrid: Fundación FOESSA.

Giulietti, C., Guzi, M., Kahanec, M., Zimmermann, K.F. (2011) "Unemployment Benefits and Immigration: Evidence from the EU”, IZA Discussion Papers, 6075.

Gómez-Salvador, R. and Leiner-Killinger, N. (2008), An Analysis of Youth Unemployment in the Euro Area, Occasional Paper Series, 89, European Central Bank, Frankfurt am Main.

Goodam, S.W. (2010), "Integration Requirements for Integration's Sake? Identifying, Categorising and Comparing Civic Integration Policies", Journal of Ethnic and Migration Studies, 36(5), 753-772.

Gradín, C., del Río, C. (2013), "El desempleo de inmigrantes, mujeres y jóvenes”, in Fundación Alternativas [ed.]: Informe sobre la Desigualdad 2013. Pp.135-192

Gradín, C., Cantó, O., del Río, C. (2012): "Measuring employment deprivation among households in the EU”, ECINEQ WP 2012 - 247.

Guio, A.-C. (2005), 'Material Deprivation in the EU', Statistics in Focus, Eurostat, Statistics in Focus 21/2005, European Communities: Luxembourg.

Guio, A.-C., Engsted-Maquet, I. (2007), Non-Income dimension in EU-SILC: Material deprivation and poor housing, in Comparative EU Statistics on Income and Living Conditions: Issues and Challenges, Helsinki,

Guio, A.-C. (2009), 'What can be learned from deprivation indicators in Europe?', Eurostat methodologies and working papers, Eurostat, Luxembourg.

Hickman, M., Crowley, H., Mai, N. (2009), Immigration and social cohesion in the UK, York: Joseph Rowntree Foundation.

Hildebrandt, V., Pi Alperin, M.N., Van Kerm, P. (2012), "Measuring and accounting for the deprivation gap of Portuguese immigrants in Luxembourg", CEPS/INSTEAD Working Paper 2102-13. Luxembourg.

Hipólito, S., Ramos-Lobo, R., Sanromá, E. (2010), "Movilidad ocupacional de los inmigrantes en una economía de bajas cualificaciones. El caso de España", Xarxa de Referència en Economia Aplicada (XREAP), 2010-6.

IDEA (2009), "Europe: the continent of immigrants: Trends, structures and policy implications", IDEA Working Papers, 13, Centre of Migration Research, Warsaw. 
Izquierdo, M., Lacuesta, A., Vegas, R. (2009), "Assimilation of Immigrants in Spain: A Longitudinal Analysis”, Labour Economics, 16(6): 669-678.

Jacobs, D., Rea, A. (2007), "The end of national models? Integration courses and citizenship trajectories in Europe", International Journal on Multicultural Societies, 9(2), pp.264283.

Jin, R.L., Shah, C.P., Svoboda, T.J. (1995), "The impact of unemployment on health: a review of the evidence". Canadian Medical Association Journal, 153(5): 529-540.

Joppke, C. (2007), "Beyond National Models: Civic Integration Policies for Immigrants in Western Europe", West European Politics, 30(1), pp. 1-22.

Joppke, C. (2010), Citizenship and Immigration, Cambridge: The Polity Press.

Kahanec, M., Zimmermann, K.F. (2009), 'Migration in an enlarged EU: A challenging solution?', in F. Keereman and I. Székely (eds), Five Years of an Enlarged EU: A positive sum game, Berlin: Springer, 63-94.

Kahanec, M., Zimmermann, K.F. (2010), EU labour markets after post-enlargement migration, Berlin: Springer

Kakawani, N., Silber, J. [eds.], (2007), The Many Dimensions of Poverty, Palgrave Macmillan: Basingstoke

Koopmans, R. (2008), "Tradeoffs between Equality and Difference. Immigrant Integration, Multiculturalism, and the Welfare State in Cross-National Perspective", Wissenschafstzentrum Berlin für Sozialförschung (WZB), Discussion Paper SP IV 2008701.

Kraal, K., Roosblad, J., Wrench, J. [eds.] (2009), Equal Opportunities and Ethnic Inequality in European Labour Markets: Discrimination, Gender and Policies of Diversity, Amsterdam: IMISCOE-AUP Series.

Kraszewska, K. (2011), Indicators of Immigrant Integration. A Pilot Study, Eurostat Methodologies \& Working Papers, Luxembourg: Publications Office of the European Union, 2011.

Maitre, B, Nolan, B., Whelan, C.T. (2012), "Reassessing the EU 2020 Poverty Target. An Analysis of EU-SILC 2009”. Geary WP2012/13 May 2012

Martín, A., López, P., Molina, O. (2011), "Movilidad ascendente de la inmigración en España: ¿asimilación o segmentación ocupacional?”, Papers, 96(4): 1311-1338.

Martínez, R. (2010): "Baja renta y privación material de la población inmigrante en España”, Presupuesto y Gasto Público, no 61 (4/2010), 2010, 311-336.

Martínez, R., Tetoofa, A., Ruiz-Huerta, J. (2014), "Material deprivation in Canada and Europe: comparing the Ontario Material Deprivation Index with EU-SILC indicators", Paper to be presented at the Ninth International Conference on Interdisciplinary Social Sciences - University of British Columbia, Vancouver, Canada, 11-13 June 2014. 
Martínez, R., Alameh, L.I., Ruiz-Huerta, J. (2014), "Who is at Risk of Poverty and Social Exclusion in Canada? A comparative analysis within the Europe 2020 framework", Paper to be presented at the Ninth International Conference on Interdisciplinary Social Sciences University of British Columbia, Vancouver, Canada, 11-13 June 2014.

Muñoz de Bustillo, R., Antón, J.I. (2011), "From Rags to Riches? Immigration and Poverty in Spain", Population Research and Policy Review, 30(5), 661-176.

Nelson, G. (2011), "Measuring Poverty: The Official U.S. Measure and Material Hardship", Poverty \& Public Policy, 3(3), pp. 1-35.

Nieto, S., Matano, A., Ramos, R (2013): "Skill Mismatches in the EU: Immigrants vs. Natives”, X Jornadas de Economía Laboral, Madrid 11-12 July 2013.

Nolan, B., Whelan, C.T. (2007), "On the multidimensionality of poverty and social exclusion"; in J. Micklewright and S.P. Jenkins [eds.], Poverty and Inequality: New Directions. Oxford University Press, Oxford.

Nolan, B., Whelan, C.T. (2009), "Using Non-Monetary Deprivation Indicators to Analyse Poverty and Social Exclusion in Rich Countries: Lessons from Europe? School of Applied Social Science, UCD, The Economic and Social Research Institute, Dublin, WP09/11.

Nolan, B., Whelan, C.T. (2010), "Using non-monetary deprivation indicators to analyze poverty and social exclusion: Lessons from Europe?", Journal of Policy Analysis and Management, Vol. 29, No. 2, pp. 305-325.

Nolan, B., Whelan, C.T. (2011), Poverty and Deprivation in Europe, Oxford: Oxford University Press.

Notten, G. (2013), "Child deprivation in Ontario: A (less than perfect) comparison with Europe”, UNU-Merit Working Paper Series, \#2013-030, Maastricht.

OECD (2012), Settling In: OECD Indicators of Immigrant Integration 2012. Paris: OECD.

Paul, K.I., Moser, K. (2009), "Unemployment impairs mental health: meta-analyses", Journal of Vocational Behavior, 74: 264-282

Penninx, R. (2004), "Integration of Migrants: Economic, Social, Cultural and Political Dimensions”, UNECE European Population Forum 2004, Geneva, 12-14 January 2004.

Pi-Alperin, M. (2008), "A comparison of multidimensional deprivation characteristics between natives and immigrants in Luxembourg”, IRISS WP 2008-14, December 2008.

Picot, G., Sweetman, A. (2005), “The Deteriorating Economic Well-Being of Immigrants and Possible Causes: Update 2005", Statistics Canada Research Paper Series, 11F0019MIE No. 262.

Presupuesto y Gasto Público (2010): Immigration and Public Policies in Spain. Vol. 61 (4-2010) Instituto de Estudios Fiscales. 
Simón, H., Ramos, R., Sanromá, E. (2011), "Occupational Mobility of Immigrants in a Low Skilled Economy: The Spanish Case", IZA Discussion Papers 5581, Institute for the Study of Labor (IZA).

Simón, H., Sanromá, E., Ramos, R. (2008), "Labour Segregation and Immigrant and Native-born Wage Distributions in Spain: An Analysis Using Matched EmployerEmployee Data", Spanish Economic Review, 10(2):135-168.

Silber, J., Deutsh, J. (2005), "Measuring multidimensional poverty: an empirical comparison of various approaches". Review of Income and Wealth, No. 1/2005, 145-174.

Social Protection Committee (2011), The social dimension of the Europe 2020 strategy. A report of the Social Protection Committee. Summary, Luxembourg: Publications Office of the European Union, 2011.

Thorbecke, E. (2007), "Multidimensional poverty: Conceptual and measurement issues", in: Kakawani, N., Silber, J. (Eds.), The Many Dimensions of Poverty. Palgrave, Macmillan, Basingstoke.

Tsui, K.Y. (2002), "Multidimensional Poverty Indices," Social Choice \& Welfare, 19, 69-93.

Urbanos, R, González, B (2013): "Desempleo y salud: un análisis de la repercusión de la crisis económica sobre la salud de los españoles", Estudios de Economía Aplicada, 31(2), pp. 303-326.

Whelan, C.T., Nolan, B., Maitre, B. (2008), "Measuring Material Deprivation in the Enlarged EU," ESRI Working Paper num. 249.

Widmaier, S, Dumont, J-C. (2011), "Are recent immigrants different? A new profile of immigrants in the OECD based on DIOC 2005/06", OECD Social, Employment and Migration Working Papers $\mathrm{N}^{\circ}$ 126, Directorate for Employment, Labour and Social Affairs, OECD. 


\section{ANNEX}

Table A.1. Material deprivation indicators for Ontario population, year 2009

\begin{tabular}{lc}
\hline & $\begin{array}{c}\% \\
\text { People }\end{array}$ \\
\hline $\begin{array}{l}\text { Household cannot afford to obtain dental care when needed. } \\
\text { Household cannot afford to replace or repair broken or damaged appliances such as a vacuum } \\
\text { cleaner or a toaster. }\end{array}$ & 10,1 \\
Household cannot afford to eat fresh fruit and vegetables every day. & 6,4 \\
Household cannot afford to have each member of the household have a hobby or leisure & 5,0 \\
activity. & 4,9 \\
Household cannot afford to have friends or family over for a meal at least once a month & \\
Household cannot afford to have appropriate clothes for job interviews or other special & 3,1 \\
occasions. & 2,4 \\
Household cannot afford to buy some small gifts for family or friends at least once a year. & 2,0 \\
Household cannot afford to eat meat, fish or a vegetarian equivalent at least every other day. & 0,6 \\
Dwelling not free of pests and insect such as mice, bedbugs or cockroaches. & \\
Household cannot afford to get around the community, either by having a car or by taking the & 0,6 \\
bus or an equivalent mode of transportation. & \\
\% People living in households reporting deprivation: & 19,5 \\
1+ items & 9,8 \\
$2+$ items & 5,6 \\
$3+$ items & 2,9 \\
$4+$ items & 1,7 \\
\hline+ items
\end{tabular}

Notes: The table shows the percentage of people living in households reporting deprivation, related to the total population answering the material deprivation module. Households answering "Do not know" simultaneously to all the deprivation questions (about 13\% of the sample) have been excluded from calculations.

Source: Authors' elaboration, using the SLID-2009 Public Use Microdata File. 
Table A.2. Demographic shares of immigrants by age group, 2009

\begin{tabular}{lrrrrrrr}
\hline & GE & SP & FR & IT & UK & CN & ONT \\
\hline Natives & 91 & 91 & 87 & 91 & 87 & 81 & 73 \\
Aged 0-24 & 23 & 23 & 25 & 21 & 25 & 24 & 22 \\
Aged 25-59 & 46 & 48 & 41 & 44 & 40 & 42 & 38 \\
Aged 59+ & 21 & 21 & 20 & 25 & 21 & 15 & 14 \\
Immigrants & 9 & 9 & 13 & 9 & 13 & 19 & 27 \\
Aged 0-24 & 2 & 3 & 5 & 3 & 5 & 6 & 9 \\
Aged 25-59 & 3 & 5 & 6 & 5 & 7 & 9 & 12 \\
Aged 59+ & 4 & 1 & 3 & 1 & 2 & 4 & 6 \\
Total & 100 & 100 & 100 & 100 & 100 & 100 & 100 \\
\hline
\end{tabular}

Source: Authors' elaboration, using cross-sectional 2009-SILC anonymised user database, version 01-08-2011, for European countries, and SLID-2009 Public Use Microdata File for Canada. 
Table A.3. Low income, material deprivation, low work intensity and at-risk-ofpoverty or social exclusion rates by immigrant status and age group, 2009

\begin{tabular}{|c|c|c|c|c|}
\hline & Low income & $\begin{array}{c}\text { Severe material } \\
\text { deprivation }\end{array}$ & $\begin{array}{l}\text { Very low work } \\
\text { intensity }\end{array}$ & $\begin{array}{l}\text { At risk of } \\
\text { poverty or } \\
\text { exclusion }\end{array}$ \\
\hline \multicolumn{5}{|c|}{ Total population (aged <60) } \\
\hline FR & 0,137 & 0,062 & 0,085 & 0,204 \\
\hline GE & 0,154 & 0,062 & 0,108 & 0,210 \\
\hline SP & 0,183 & 0,038 & 0,069 & 0,230 \\
\hline UK & 0,163 & 0,039 & 0,128 & 0,230 \\
\hline $\mathrm{CN}$ & 0,195 & $(\mathrm{Na})$ & 0,107 & $0,255(\mathrm{~s})$ \\
\hline IT & 0,185 & 0,075 & 0,088 & 0,259 \\
\hline Ontario & 0,196 & 0,057 & 0,115 & 0,261 \\
\hline \multicolumn{5}{|c|}{ Immigrants (aged $<60$ ) } \\
\hline FR & 0,305 & 0,132 & 0,151 & 0,388 \\
\hline GE & 0,208 & 0,071 & 0,129 & 0,267 \\
\hline SP & 0,300 & 0,116 & 0,068 & 0,378 \\
\hline UK & 0,268 & 0,083 & 0,162 & 0,326 \\
\hline $\mathrm{CN}$ & 0,280 & $(\mathrm{Na})$ & 0,127 & $0,362(\mathrm{~s})$ \\
\hline $\mathrm{IT}$ & 0,302 & 0,170 & 0,057 & 0,404 \\
\hline Ontario & 0,247 & 0,090 & 0,098 & 0,326 \\
\hline \multicolumn{5}{|c|}{ Immigrants: aged 25-59 } \\
\hline FR & 0,249 & 0,120 & 0,142 & 0,340 \\
\hline GE & 0,191 & 0,063 & 0,140 & 0,249 \\
\hline SP & 0,259 & 0,103 & 0,069 & 0,339 \\
\hline UK & 0,214 & 0,072 & 0,137 & 0,269 \\
\hline $\mathrm{CN}$ & 0,249 & $(\mathrm{Na})$ & 0,121 & $0,328(\mathrm{~s})$ \\
\hline IT & 0,272 & 0,161 & 0,059 & 0,378 \\
\hline Ontario & 0,205 & 0,069 & 0,085 & 0,275 \\
\hline \multicolumn{5}{|c|}{ Immigrants: aged under 25} \\
\hline FR & 0,369 & 0,146 & 0,162 & 0,443 \\
\hline GE & 0,236 & 0,084 & 0,110 & 0,297 \\
\hline SP & 0,369 & 0,139 & 0,067 & 0,443 \\
\hline UK & 0,340 & 0,098 & 0,197 & 0,404 \\
\hline $\mathrm{CN}$ & 0,328 & $(\mathrm{Na})$ & 0,137 & $0,414(\mathrm{~s})$ \\
\hline IT & 0,352 & 0,186 & 0,055 & 0,447 \\
\hline Ontario & 0,306 & 0,120 & 0,117 & 0,398 \\
\hline
\end{tabular}

Note: (Na) Not available. (s) Estimated adjusting upwards the risk of low income or low work intensity by using the same proportions derived for Ontario.

Source: Authors' elaboration, using cross-sectional 2009-SILC anonymised user database, version 01-08-2011, for European countries, and SLID-2009 Public Use Microdata File for Canada. 
Table A.4. Material deprivation and at-risk-of-poverty or social exclusion rates using different deprivation indicators and thresholds, 2009

\begin{tabular}{|c|c|c|c|c|c|c|}
\hline & \multicolumn{3}{|c|}{ Material deprivation } & \multicolumn{3}{|c|}{ At-risk-of-poverty/exclusion } \\
\hline & SMD & MD & $\mathbf{M D}^{\prime}$ & $\begin{array}{l}\text { Using } \\
\text { SMD }\end{array}$ & $\begin{array}{r}\text { Using } \\
\text { MD }\end{array}$ & $\begin{array}{r}\text { Using } \\
\text { MD' }^{\prime}\end{array}$ \\
\hline \multicolumn{7}{|c|}{ Total population (aged <60) } \\
\hline FR & 0,062 & 0,150 & 0,181 & 0,204 & 0,256 & 0,279 \\
\hline GE & 0,062 & 0,142 & 0,160 & 0,210 & 0,250 & 0,262 \\
\hline SP & 0,038 & 0,123 & 0,208 & 0,230 & 0,280 & 0,338 \\
\hline UK & 0,039 & 0,115 & 0,149 & 0,230 & 0,265 & 0,283 \\
\hline IT & 0,075 & 0,166 & 0,235 & 0,259 & 0,313 & 0,357 \\
\hline Ontario & 0,057 & 0,100 & 0,197 & 0,261 & 0,287 & 0,340 \\
\hline \multicolumn{7}{|c|}{ Immigrants (aged $<60$ ) } \\
\hline FR & 0,132 & 0,288 & 0,332 & 0,388 & 0,462 & 0,493 \\
\hline GE & 0,071 & 0,208 & 0,224 & 0,267 & 0,349 & 0,364 \\
\hline SP & 0,116 & 0,319 & 0,464 & 0,378 & 0,489 & 0,577 \\
\hline UK & 0,083 & 0,180 & 0,208 & 0,326 & 0,365 & 0,376 \\
\hline IT & 0,170 & 0,318 & 0,412 & 0,404 & 0,478 & 0,549 \\
\hline Ontario & 0,090 & 0,149 & 0,252 & 0,326 & 0,369 & 0,422 \\
\hline
\end{tabular}

Notes: $\mathrm{SMD}=$ Severe material deprivation, using Eurostat current definition. $\mathrm{MD}=$ Material deprivation, using current 9 item deprivation list but changing threshold to $3+$ items. MD'= Material deprivation using the $3+$ item threshold for the alternative 9 items deprivation list, obtained substituting the enforced lack of three widely possessed durable goods (a television set, a washing machine and a telephone) for the following items: a) the household cannot afford a computer; b) the household cannot afford dental care for each member of the family when needed; c) the household has great difficulties in making ends meet. For Ontario, the three definitions correspond to applying the thresholds of $3+$ items, $2+$ items and $1+$ items respectively to the list of 10 indicators included in the Ontario Material Deprivation Index.

Source: Authors' elaboration, using cross-sectional 2009-SILC anonymised user database, version 01-08-2011, for European countries, and SLID-2009 Public Use Microdata File for Canada. 


\section{Graph A.1}

Material deprivation rates for immigrants with different indicators and thresholds, 2009

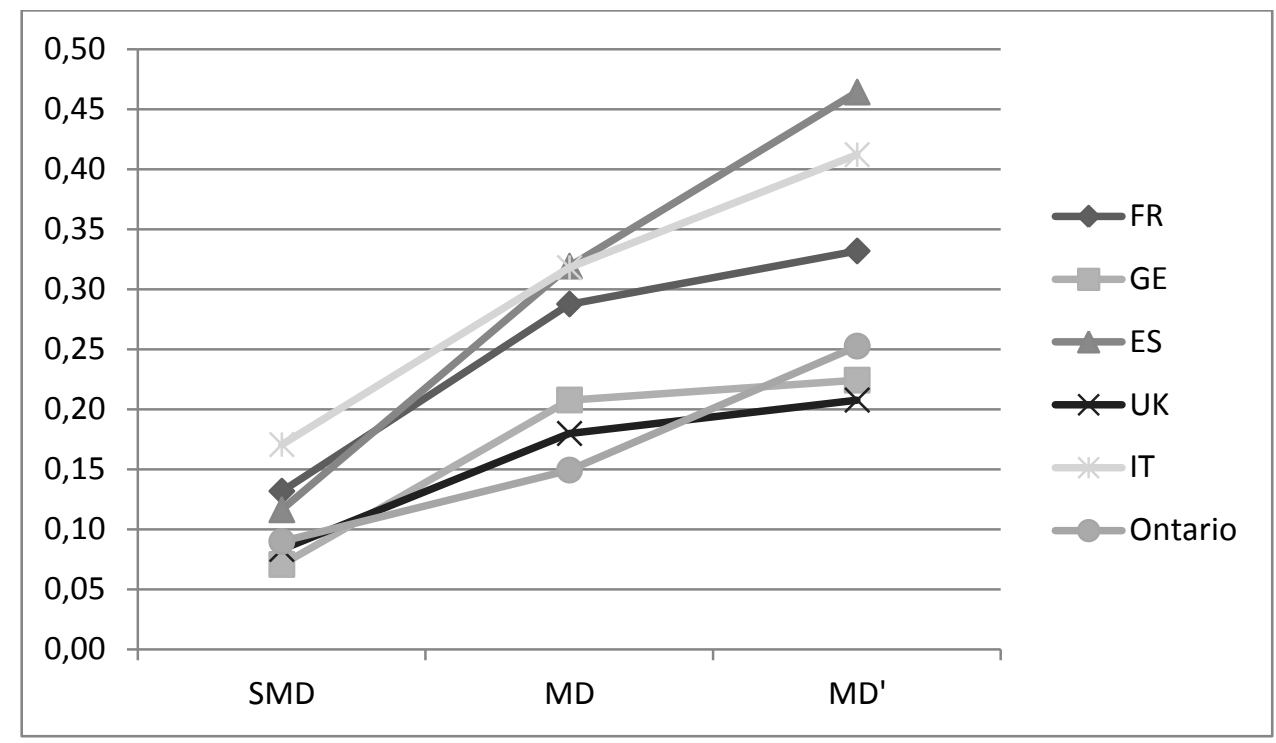

Notes: See Table A.4 for an explanation of the definitions of material deprivation used. Source: Authors' elaboration, using cross-sectional 2009-SILC anonymised user database, version 01-08-2011, for European countries, and SLID-2009 Public Use Microdata File for Canada. 
Table A.5. Headcount (H), Adjusted Headcount $\left(\mathrm{M}_{0}\right)$ and Adjusted Poverty Gap Ratios $\left(M_{1}\right)$ for different values of the dimensional threshold $k, 2009$

\begin{tabular}{|c|c|c|c|c|c|c|c|c|}
\hline & \multicolumn{3}{|c|}{$\mathrm{k}=1$} & \multicolumn{3}{|c|}{$\mathrm{k}=2$} & \multicolumn{2}{|c|}{$\mathrm{k}=3$} \\
\hline & $\mathbf{H}$ & $\mathbf{M}_{0}$ & $\mathbf{M}_{1}$ & $\mathbf{H}$ & $\mathbf{M}_{0}$ & $\mathbf{M}_{1}$ & $\mathbf{H}=\mathbf{M}_{0}$ & $\mathbf{M}_{1}$ \\
\hline \multicolumn{9}{|c|}{ Total population (aged <60) } \\
\hline FR & 0,256 & 0,124 & 0,085 & 0,087 & 0,067 & 0,046 & 0,029 & 0,021 \\
\hline GE & 0,250 & 0,135 & 0,094 & 0,110 & 0,088 & 0,063 & 0,044 & 0,033 \\
\hline SP & 0,280 & 0,125 & 0,085 & 0,078 & 0,057 & 0,041 & 0,017 & 0,013 \\
\hline UK & 0,265 & 0,135 & 0,095 & 0,108 & 0,083 & 0,061 & 0,034 & 0,025 \\
\hline IT & 0,313 & 0,146 & 0,103 & 0,104 & 0,076 & 0,056 & 0,021 & 0,017 \\
\hline Ontario & 0,287 & 0,137 & 0,084 & 0,097 & 0,073 & 0,050 & 0,026 & 0,019 \\
\hline \multicolumn{9}{|c|}{ Immigrants (aged $<60$ ) } \\
\hline FR & 0,462 & 0,248 & 0,163 & 0,203 & 0,162 & 0,111 & 0,078 & 0,057 \\
\hline GE & 0,349 & 0,181 & 0,124 & 0,147 & 0,114 & 0,079 & 0,048 & 0,036 \\
\hline SP & 0,489 & 0,229 & 0,162 & 0,172 & 0,123 & 0,084 & 0,027 & 0,020 \\
\hline UK & 0,365 & 0,203 & 0,145 & 0,185 & 0,143 & 0,106 & 0,060 & 0,048 \\
\hline IT & 0,478 & 0,226 & 0,154 & 0,176 & 0,125 & 0,085 & 0,024 & 0,019 \\
\hline Ontario & 0,369 & 0,165 & 0,098 & 0,097 & 0,074 & 0,052 & 0,028 & 0,021 \\
\hline \multicolumn{9}{|c|}{ Immigrants: aged 25-59 } \\
\hline FR & 0,413 & 0,217 & 0,148 & 0,172 & 0,136 & 0,096 & 0,066 & 0,049 \\
\hline GE & 0,316 & 0,172 & 0,123 & 0,147 & 0,116 & 0,083 & 0,054 & 0,041 \\
\hline SP & 0,454 & 0,207 & 0,151 & 0,144 & 0,104 & 0,072 & 0,024 & 0,018 \\
\hline UK & 0,311 & 0,173 & 0,127 & 0,157 & 0,122 & 0,092 & 0,052 & 0,042 \\
\hline IT & 0,452 & 0,208 & 0,144 & 0,153 & 0,109 & 0,074 & 0,020 & 0,015 \\
\hline Ontario & 0,327 & 0,142 & 0,086 & 0,078 & 0,059 & 0,040 & 0,020 & 0,015 \\
\hline \multicolumn{9}{|c|}{ Immigrants: aged under 25} \\
\hline FR & 0,520 & 0,284 & 0,180 & 0,240 & 0,191 & 0,127 & 0,092 & 0,066 \\
\hline GE & 0,405 & 0,197 & 0,126 & 0,148 & 0,112 & 0,072 & 0,038 & 0,027 \\
\hline SP & 0,547 & 0,266 & 0,181 & 0,218 & 0,156 & 0,104 & 0,032 & 0,023 \\
\hline UK & 0,440 & 0,244 & 0,170 & 0,222 & 0,171 & 0,126 & 0,070 & 0,057 \\
\hline IT & 0,520 & 0,254 & 0,170 & 0,212 & 0,151 & 0,104 & 0,030 & 0,024 \\
\hline Ontario & 0,430 & 0,198 & 0,116 & 0,125 & 0,096 & 0,069 & 0,039 & 0,029 \\
\hline
\end{tabular}

Note: Values obtained using the intermediate material deprivation index in Table A.4.

Source: Authors's elaboration using cross-sectional 2009-SILC anonymised user database, version 01-08-2011, for European countries, and SLID-2009 Public Use Microdata File for Canada. 
Table A.6. $\mathrm{H}, \mathrm{M}_{0}$ and $\mathrm{M}_{1}$ measures for different values of $k$ : $\mathrm{EU}-5=100$

\begin{tabular}{|c|c|c|c|c|c|c|c|c|}
\hline & \multicolumn{3}{|c|}{$\mathrm{k}=1$} & \multicolumn{3}{|c|}{$k=2$} & \multicolumn{2}{|c|}{$k=3$} \\
\hline & $\mathbf{H}$ & $\mathbf{M}_{0}$ & $\mathbf{M}_{1}$ & $\mathbf{H}$ & $\mathbf{M}_{0}$ & $\mathbf{M}_{1}$ & $\mathrm{H}=\mathbf{M}_{0}$ & $\mathbf{M}_{1}$ \\
\hline \multicolumn{9}{|c|}{ Total population (aged <60) } \\
\hline FR & 94 & 93 & 92 & 89 & 91 & 86 & 99 & 94 \\
\hline GE & 91 & 101 & 102 & 113 & 119 & 118 & 153 & 152 \\
\hline SP & 103 & 94 & 92 & 80 & 77 & 76 & 59 & 61 \\
\hline UK & 97 & 102 & 103 & 111 & 111 & 115 & 117 & 116 \\
\hline IT & 115 & 110 & 111 & 107 & 102 & 104 & 72 & 76 \\
\hline Ontario & 105 & 103 & 91 & 99 & 98 & 94 & 90 & 89 \\
\hline EU-5 & 100 & 100 & 100 & 100 & 100 & 100 & 100 & 100 \\
\hline \multicolumn{9}{|c|}{ Immigrants (aged <60) } \\
\hline FR & 108 & 114 & 109 & 115 & 121 & 119 & 165 & 158 \\
\hline GE & 81 & 83 & 83 & 83 & 86 & 85 & 101 & 100 \\
\hline SP & 114 & 105 & 108 & 97 & 92 & 90 & 57 & 55 \\
\hline UK & 85 & 93 & 97 & 105 & 107 & 114 & 126 & 135 \\
\hline IT & 111 & 104 & 103 & 99 & 94 & 92 & 50 & 52 \\
\hline Ontario & 86 & 76 & 66 & 55 & 56 & 56 & 59 & 58 \\
\hline EU-5 & 100 & 100 & 100 & 100 & 100 & 100 & 100 & 100 \\
\hline
\end{tabular}

Immigrants: aged 25-59

$\begin{array}{lrrrrrrrr}\text { FR } & 106 & 111 & 107 & 111 & 116 & 115 & 152 & 147 \\ \text { GE } & 81 & 88 & 89 & 95 & 99 & 100 & 124 & 124 \\ \text { SP } & 117 & 106 & 109 & 93 & 88 & 86 & 56 & 55 \\ \text { UK } & 80 & 89 & 92 & 102 & 104 & 110 & 121 & 127 \\ \text { IT } & 116 & 107 & 104 & 99 & 93 & 89 & 46 & 46 \\ \text { Ontario } & 84 & 72 & 62 & 50 & 50 & 48 & 47 & 46 \\ \text { EU-5 } & 100 & 100 & 100 & 100 & 100 & 100 & 100 & 100\end{array}$

Immigrants: aged under 25

\begin{tabular}{lrrrrrrrr} 
FR & 107 & 114 & 109 & 115 & 122 & 119 & 176 & 169 \\
GE & 83 & 79 & 76 & 71 & 71 & 68 & 73 & 69 \\
SP & 113 & 107 & 109 & 105 & 100 & 98 & 60 & 57 \\
UK & 90 & 98 & 103 & 107 & 110 & 118 & 133 & 145 \\
IT & 107 & 102 & 103 & 102 & 97 & 97 & 58 & 61 \\
Ontario & 88 & 80 & 70 & 60 & 62 & 65 & 75 & 74 \\
EU-5 & 100 & 100 & 100 & 100 & 100 & 100 & 100 & 100 \\
\hline
\end{tabular}

Notes: EU5=100 represents the unweighted average of rates for the five EUSILC countries.

Source: Authors' elaboration using cross-sectional 2009-SILC anonymised user database, version 01-08-2011, for European countries, and SLID-2009 Public Use Microdata File for Canada. 
Table A.7. $\mathrm{H}, \mathrm{M}_{0}$ and $\mathrm{M}_{1}$ measures for different values of $\mathrm{k}$ : Relative risk for immigrants in different countries

\begin{tabular}{|c|c|c|c|c|c|c|c|c|}
\hline & \multicolumn{3}{|c|}{$\mathrm{k}=1$} & \multicolumn{3}{|c|}{$\mathrm{k}=2$} & \multicolumn{2}{|c|}{$\mathrm{k}=3$} \\
\hline & $\mathbf{H}$ & $\mathbf{M}_{0}$ & $\mathbf{M}_{1}$ & $\mathbf{H}$ & $\mathbf{M}_{0}$ & $\mathbf{M}_{1}$ & $\mathrm{H}=\mathbf{M}_{0}$ & $\mathbf{M}_{1}$ \\
\hline \multicolumn{9}{|c|}{ Immigrants: total } \\
\hline FR & 1,8 & 2,0 & 1,9 & 2,3 & 2,4 & 2,4 & 2,7 & 2,8 \\
\hline GE & 1,4 & 1,3 & 1,3 & 1,3 & 1,3 & 1,3 & 1,1 & 1,1 \\
\hline SP & 1,7 & 1,8 & 1,9 & 2,2 & 2,1 & 2,1 & 1,6 & 1,5 \\
\hline UK & 1,4 & 1,5 & 1,5 & 1,7 & 1,7 & 1,7 & 1,8 & 1,9 \\
\hline IT & 1,5 & 1,5 & 1,5 & 1,7 & 1,6 & 1,5 & 1,2 & 1,1 \\
\hline Ontario & 1,3 & 1,2 & 1,2 & 1,0 & 1,0 & 1,0 & 1,1 & 1,1 \\
\hline \multicolumn{9}{|c|}{ Immigrants: aged 25-59 } \\
\hline FR & 1,6 & 1,7 & 1,7 & 2,0 & 2,0 & 2,1 & 2,3 & 2,4 \\
\hline GE & 1,3 & 1,3 & 1,3 & 1,3 & 1,3 & 1,3 & 1,2 & 1,2 \\
\hline SP & 1,6 & 1,7 & 1,8 & 1,8 & 1,8 & 1,8 & 1,4 & 1,4 \\
\hline UK & 1,2 & 1,3 & 1,3 & 1,5 & 1,5 & 1,5 & 1,6 & 1,7 \\
\hline IT & 1,4 & 1,4 & 1,4 & 1,5 & 1,4 & 1,3 & 1,0 & 0,9 \\
\hline Ontario & 1,4 & 1,5 & 1,5 & 1,6 & 1,6 & 1,6 & 1,5 & 1,5 \\
\hline \multicolumn{9}{|c|}{ Immigrants: aged under 25} \\
\hline FR & 2,0 & 2,3 & 2,1 & 2,8 & 2,8 & 2,8 & 3,2 & 3,2 \\
\hline GE & 1,6 & 1,5 & 1,3 & 1,3 & 1,3 & 1,1 & 0,9 & 0,8 \\
\hline SP & 2,0 & 2,1 & 2,1 & 2,8 & 2,7 & 2,6 & 1,9 & 1,7 \\
\hline UK & 1,7 & 1,8 & 1,8 & 2,1 & 2,1 & 2,1 & 2,1 & 2,2 \\
\hline IT & 1,7 & 1,7 & 1,7 & 2,0 & 2,0 & 1,9 & 1,5 & 1,4 \\
\hline Ontario & 1,8 & 1,9 & 1,8 & 2,1 & 2,1 & 2,0 & 1,8 & 1,8 \\
\hline
\end{tabular}

Notes: The relative risk ratios are obtained by dividing each group's rate by the values for the whole population aged 60 or less.

Source: Authors' elaboration, using cross-sectional 2009-SILC anonymised user database, version 01-08-2011, for European countries, and SLID-2009 Public Use Microdata File for Canada. 
Graph A.2. Censored headcount ratios by dimension in 2009 , for $k=1$ and $k=2$
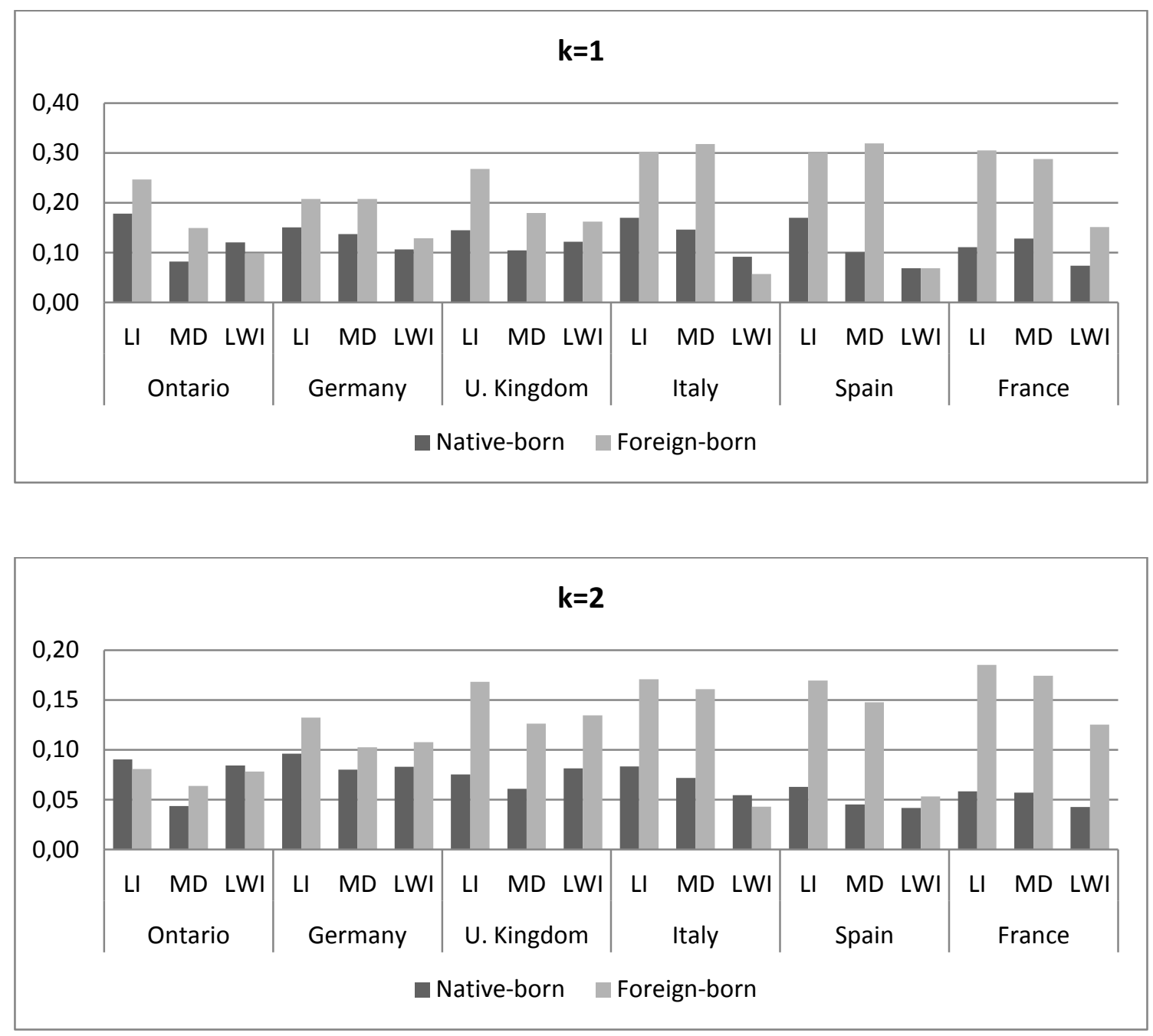

Source: Authors' elaboration, using cross-sectional 2009-SILC anonymised user database, version 01-08-2011, for European countries, and SLID-2009 Public Use Microdata File for Canada. 
Graph A.3. Dimensional breakdown of the Adjusted Headcount Ratio $\mathbf{M}_{0}$ in $2009(\mathrm{k}=1)$

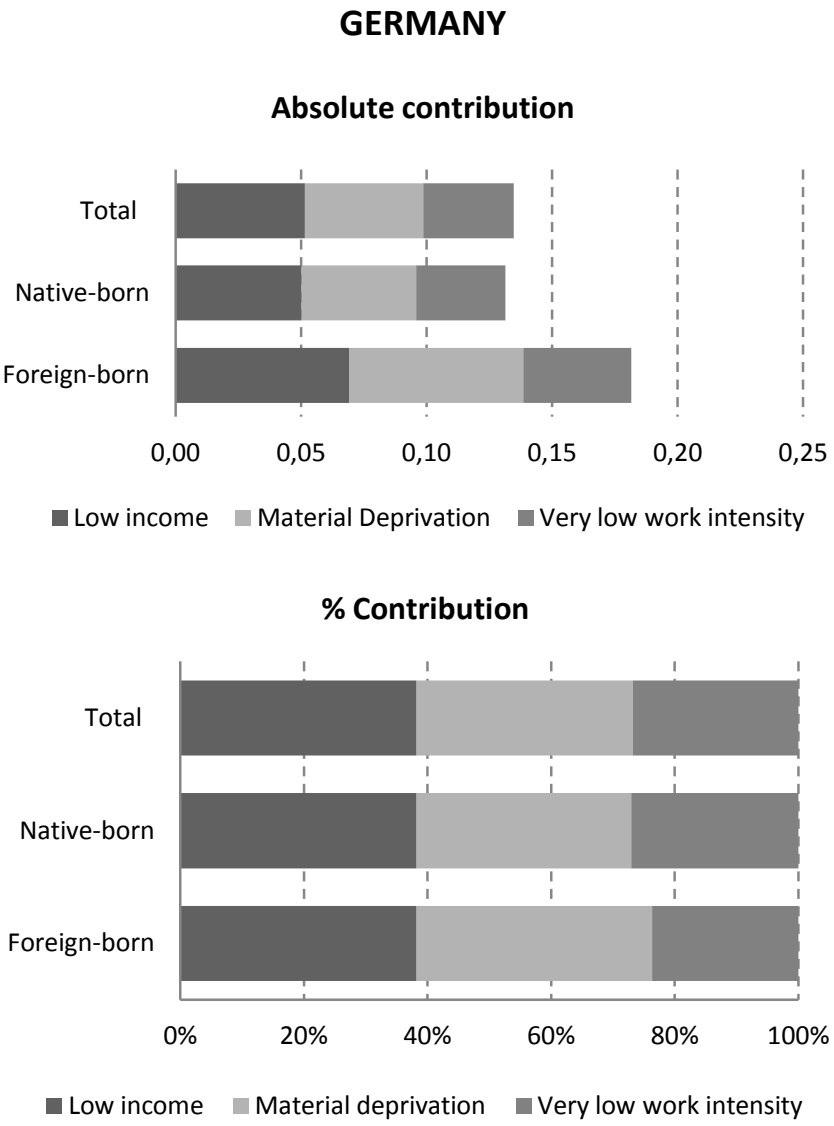

FRANCE

Absolute contribution

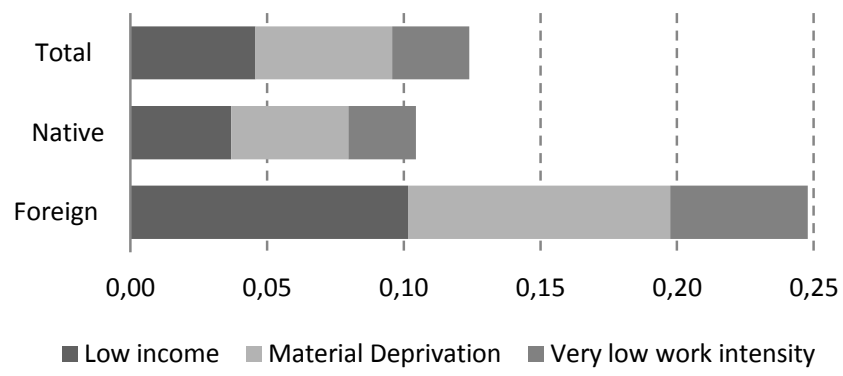

$\%$ Contribution

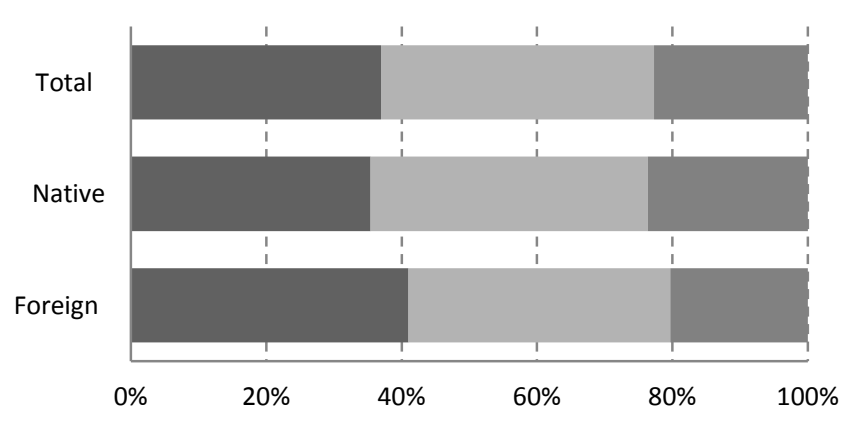

- Low income Material deprivation $\quad$ Very low work intensity

\section{UNITED KINGDOM}
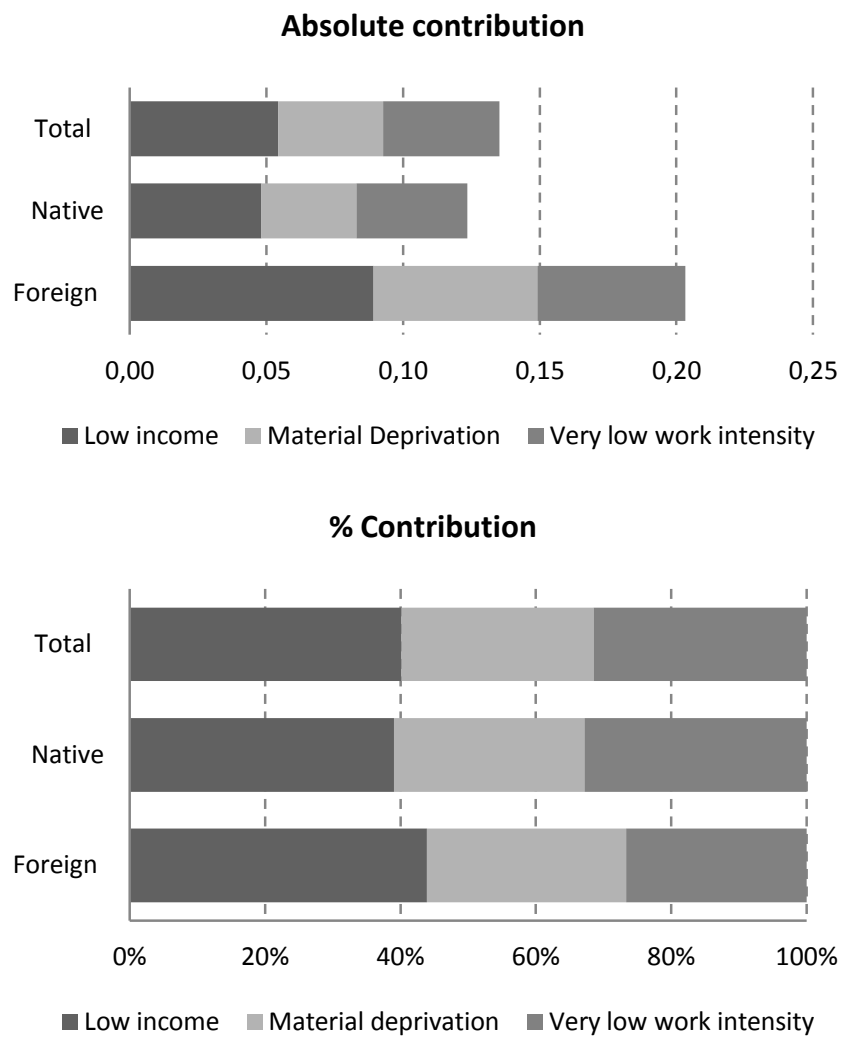

\section{ITALY}

Absolute contribution
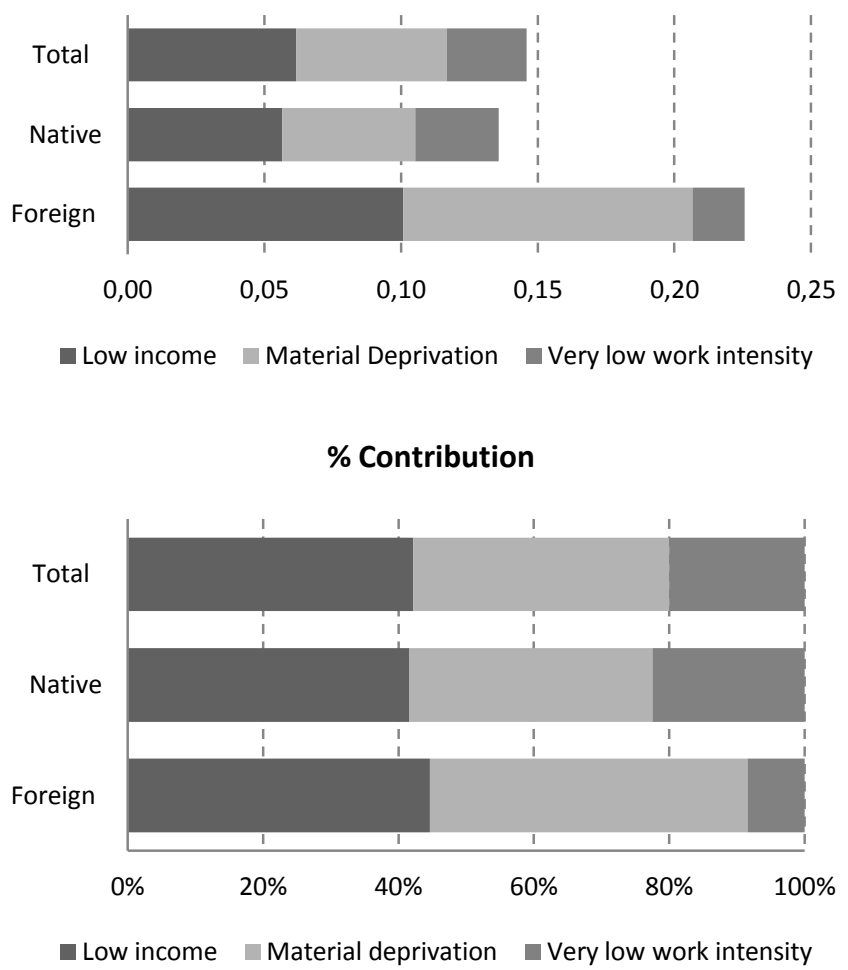


\section{Graph A.3. (Continued)}

SPAIN

Absolute contribution

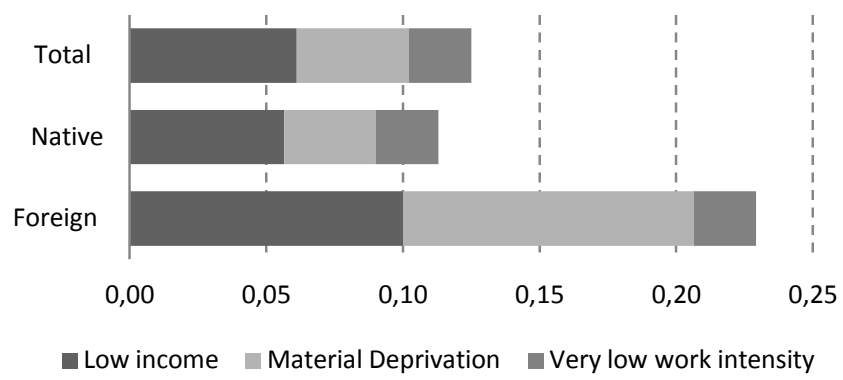

$\%$ Contribution

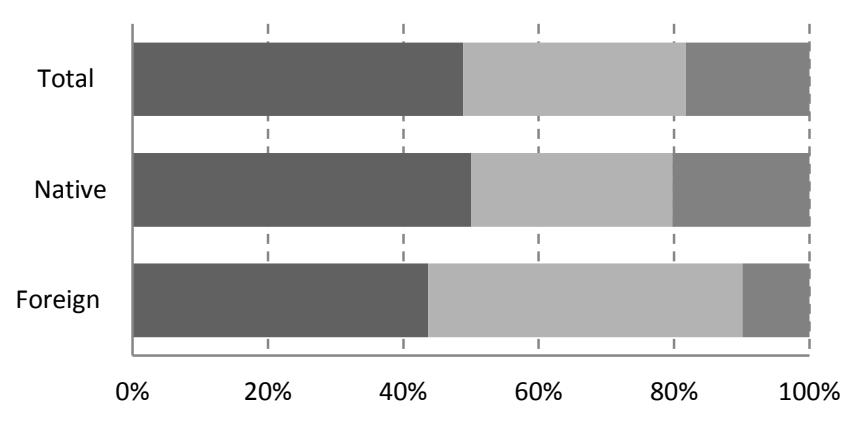

- Low income Material deprivation $\quad$ Very low work intensity
ONTARIO
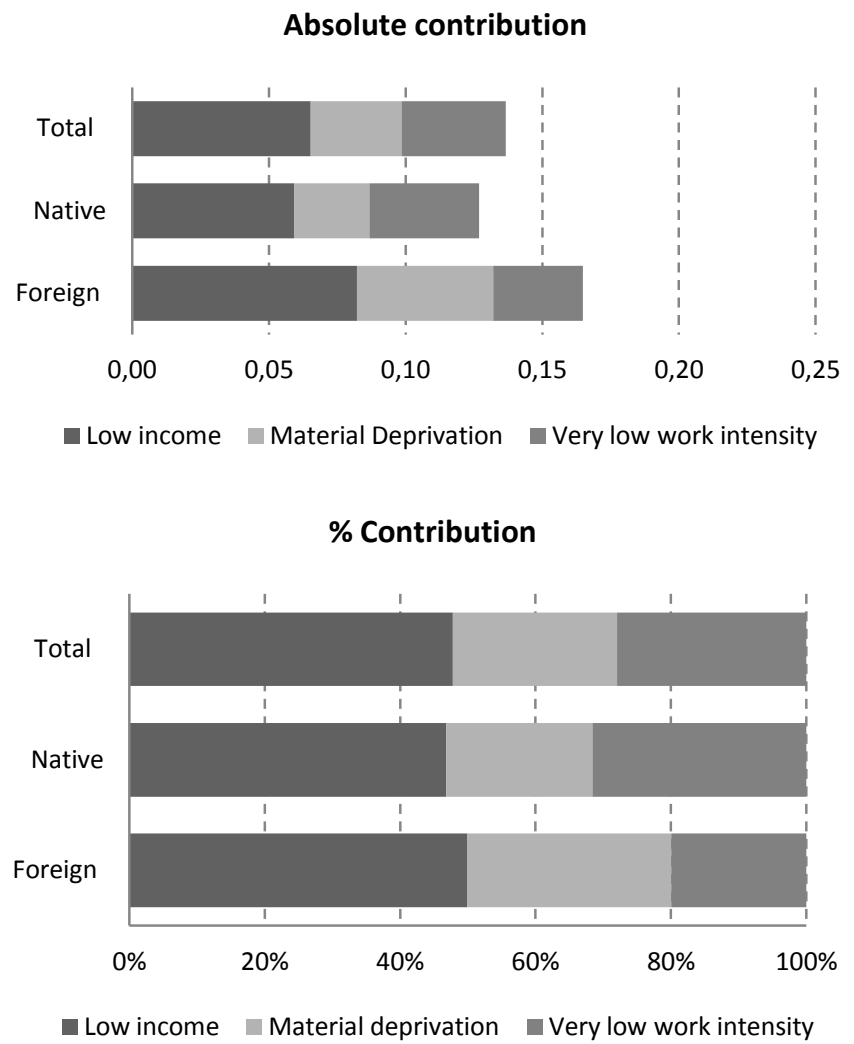

Source: Authors' elaboration, using cross-sectional 2009-SILC anonymised user database, version 0108-2011, for European countries, and SLID-2009 Public Use Microdata File for Canada. 


\section{Graph A.4. Dimensional breakdown of the Adjusted Headcount Ratio $M_{0}$ in $2009(k=2)$}

\section{GERMANY}

Absolute contribution

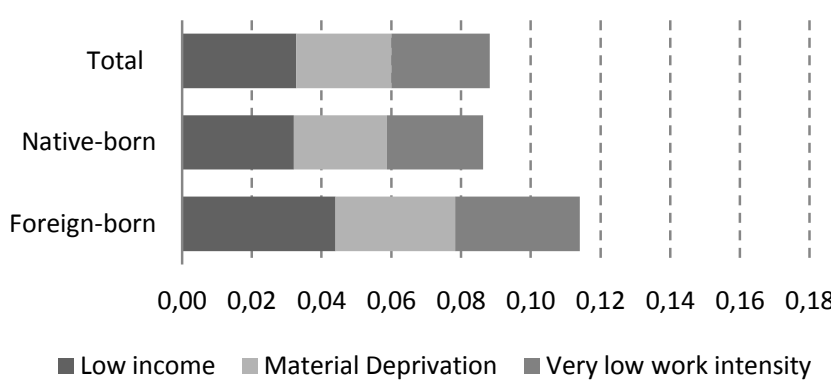

$\%$ Contribution

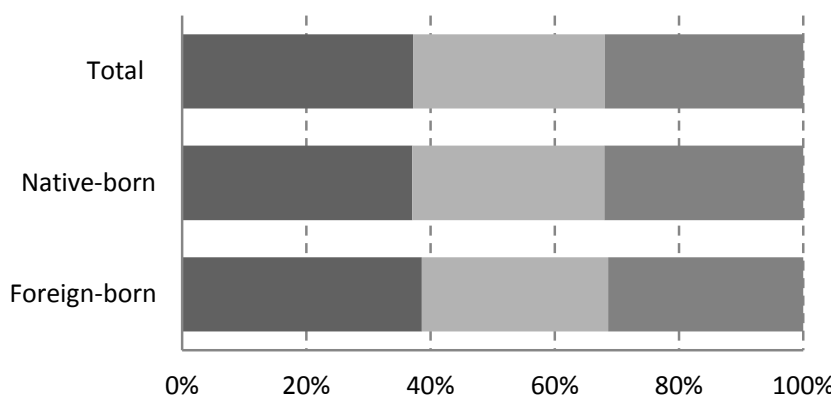

- Low income Material deprivation $\quad$ Very low work intensity

FRANCE

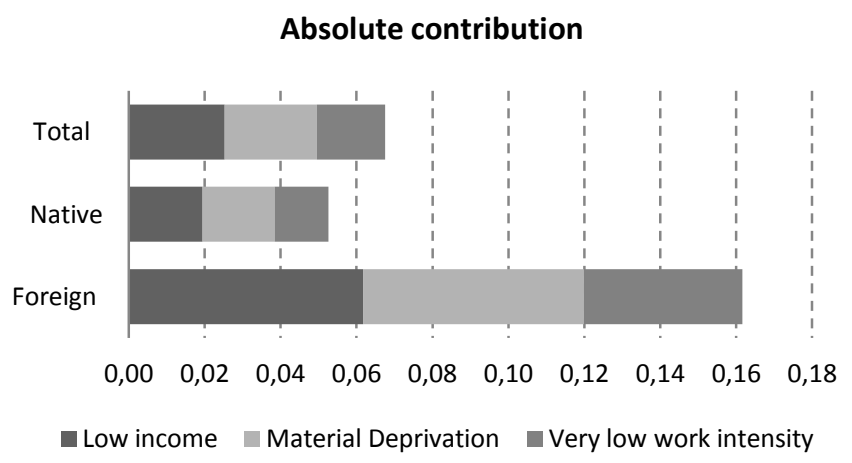

\% Contribution

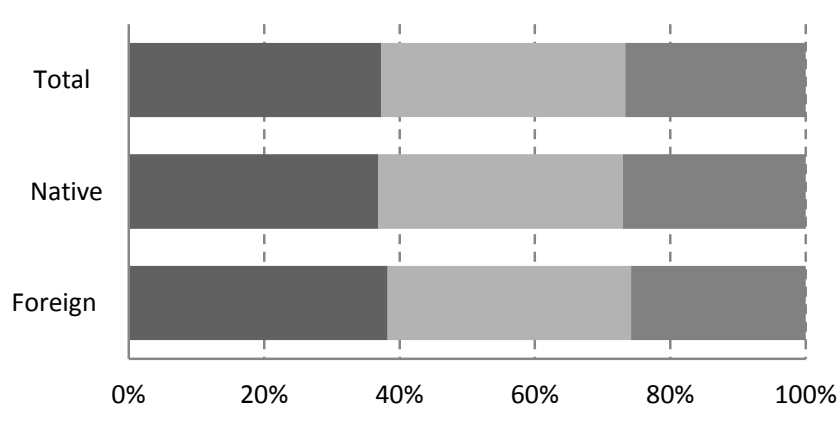

- Low income Material deprivation $\quad$ Very low work intensity
UNITED KINGDOM

Absolute contribution

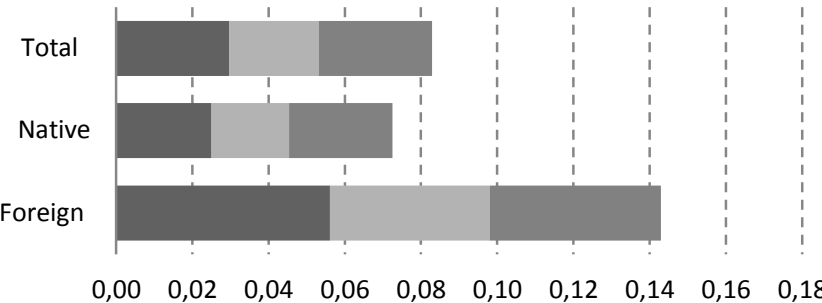

- Low income Material Deprivation Very low work intensity \% Contribution

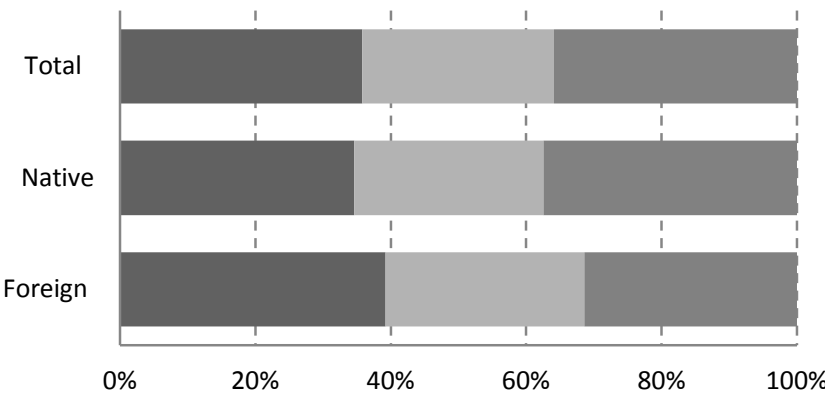

- Low income Material deprivation Very low work intensity

ITALY

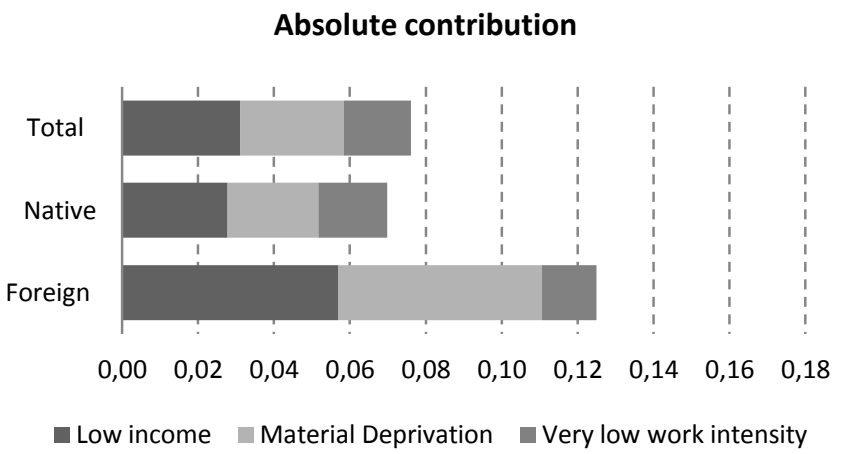

$\%$ Contribution

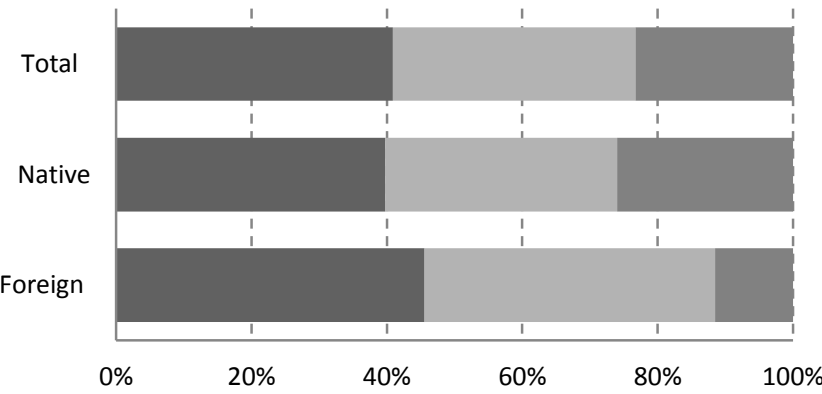

- Low income Material deprivation Very low work intensity 


\section{Graph A.4. (Continued)}

SPAIN
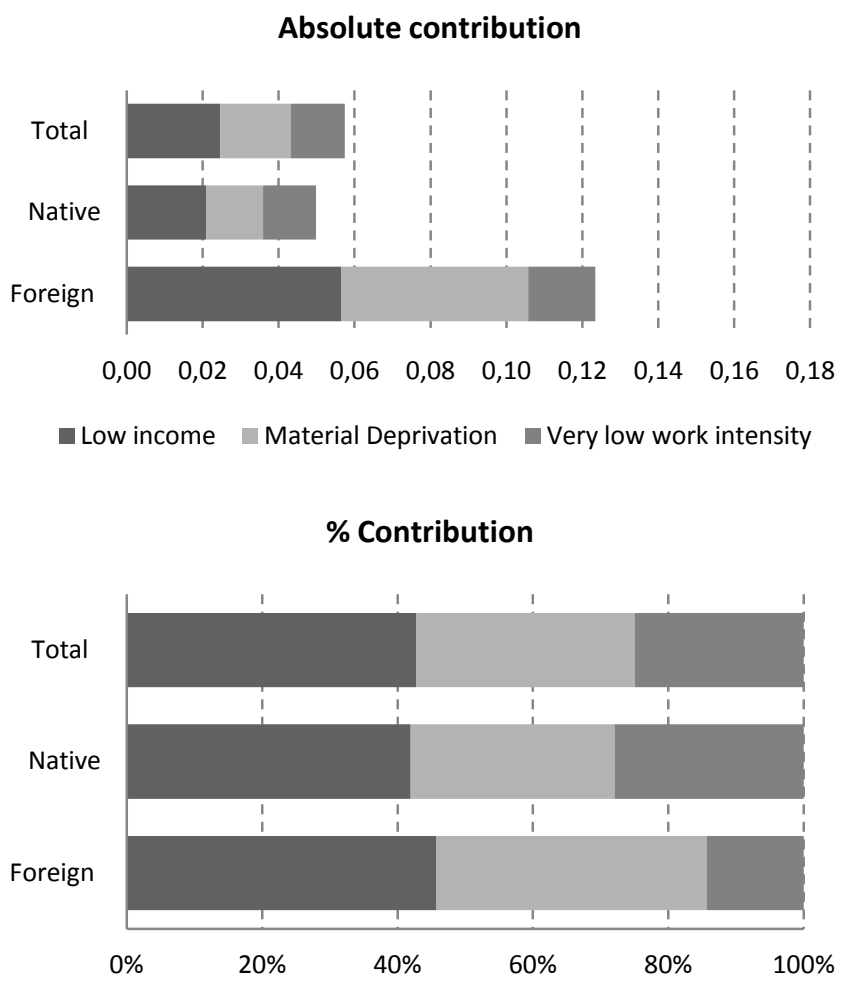

Low income Material deprivation Very low work intensity
ONTARIO

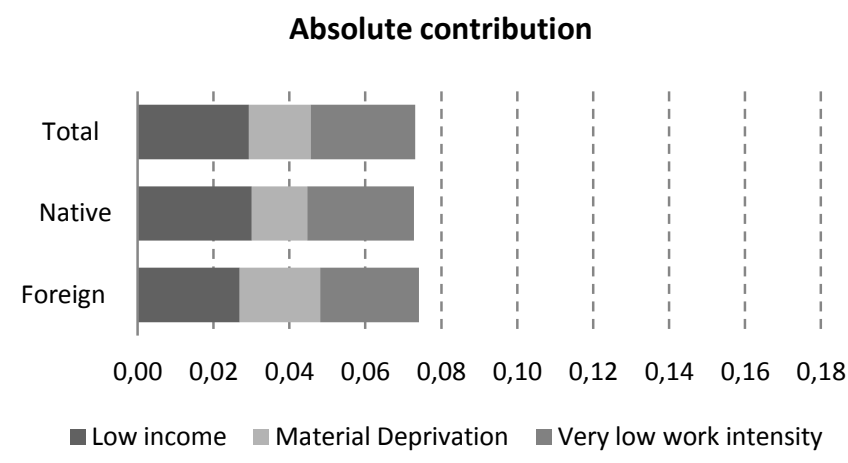

$\%$ Contribution

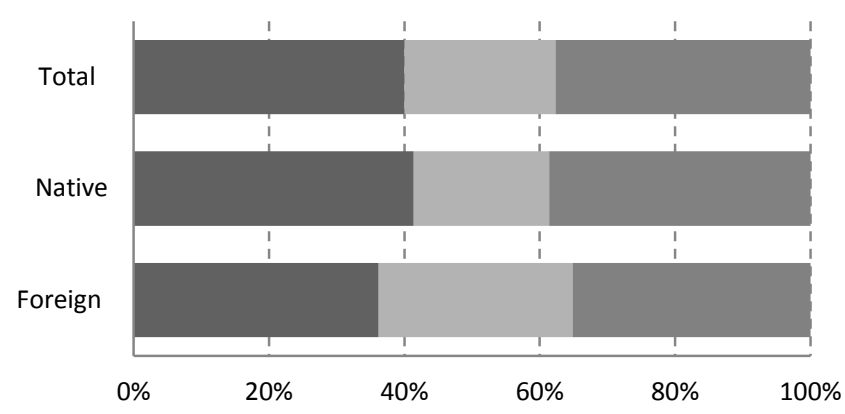

Low income Material deprivation Very low work intensity

Source: Authors' elaboration, using cross-sectional 2009-SILC anonymised user database, version 0108-2011, for European countries, and SLID-2009 Public Use Microdata File for Canada. 
Graph A.5. Trends in low income, severe material deprivation, low work intensity and AROPE measure in Spain over the period 2005-2012, for native and foreignborn persons aged 25-59
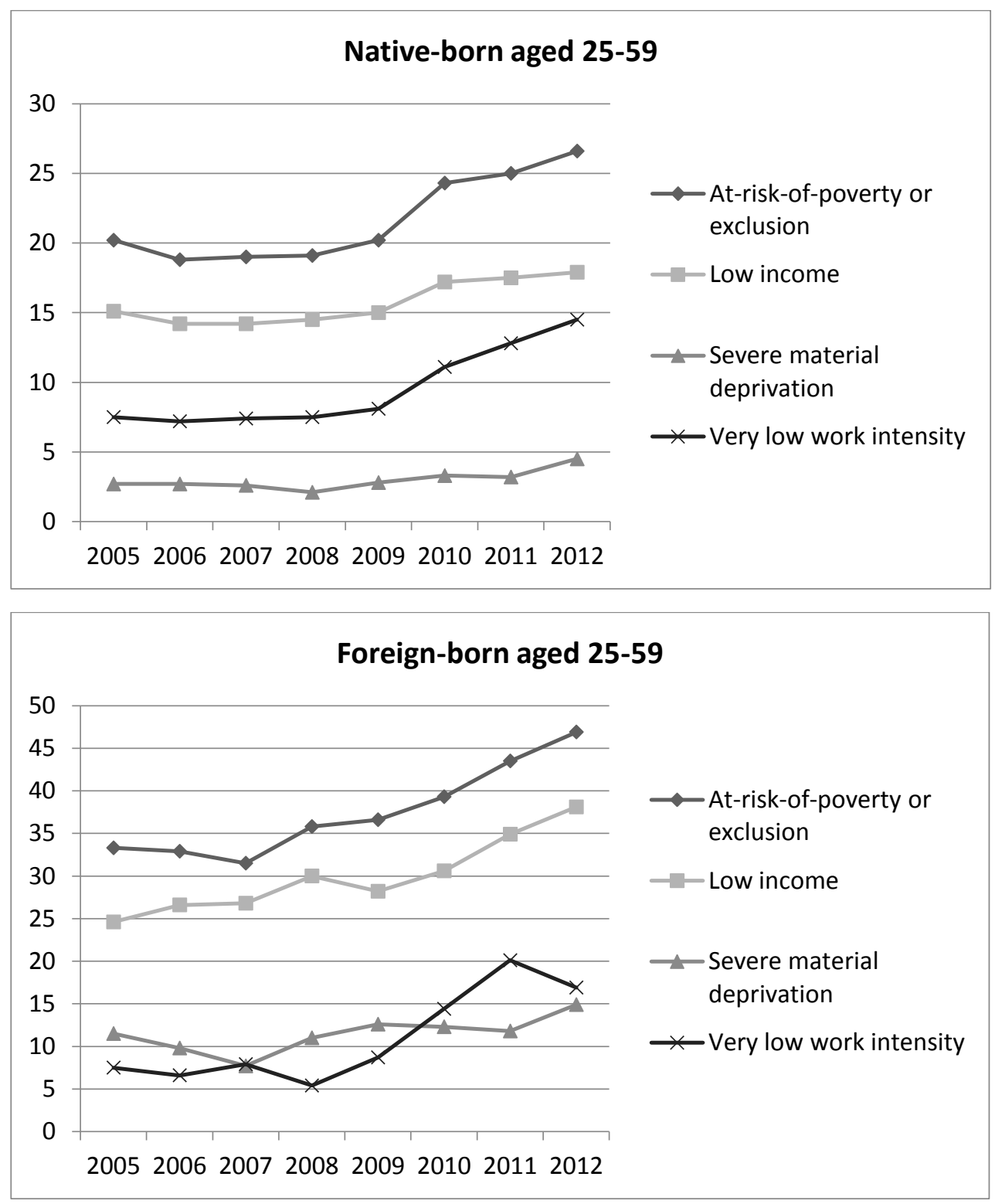

Source: Eurostat, Income and Living Conditions Database, October 2013. 
Graph A.6. Change in the Adjusted Headcount Ratio $\left(M_{0}\right)$ between 2009 and 2011

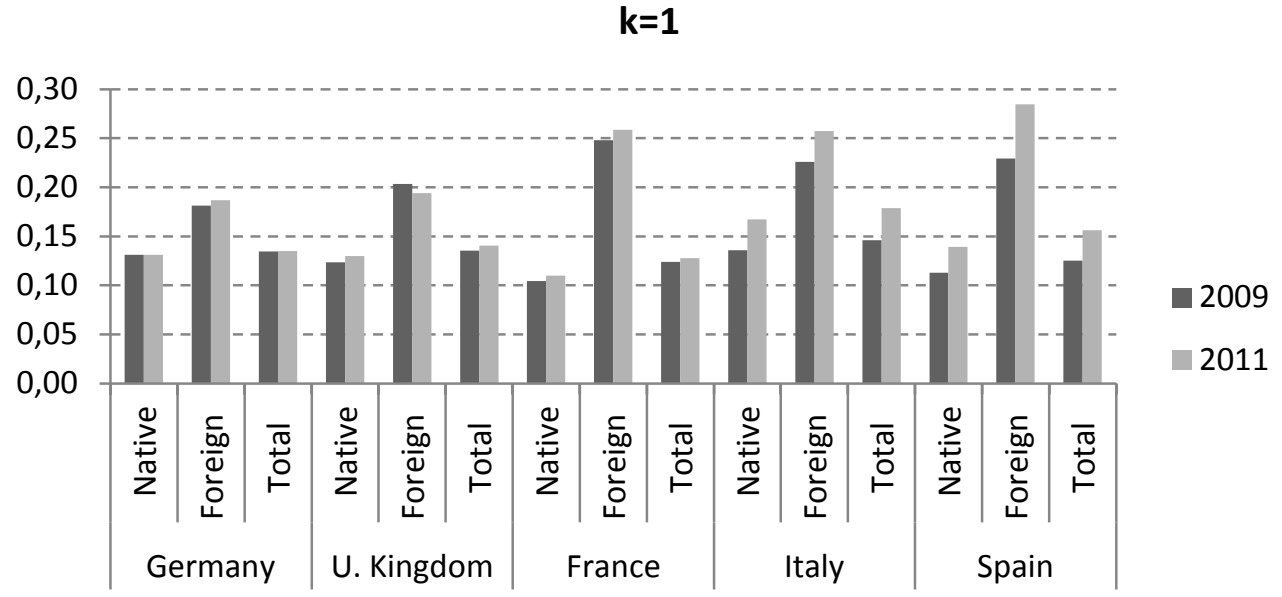

$k=2$

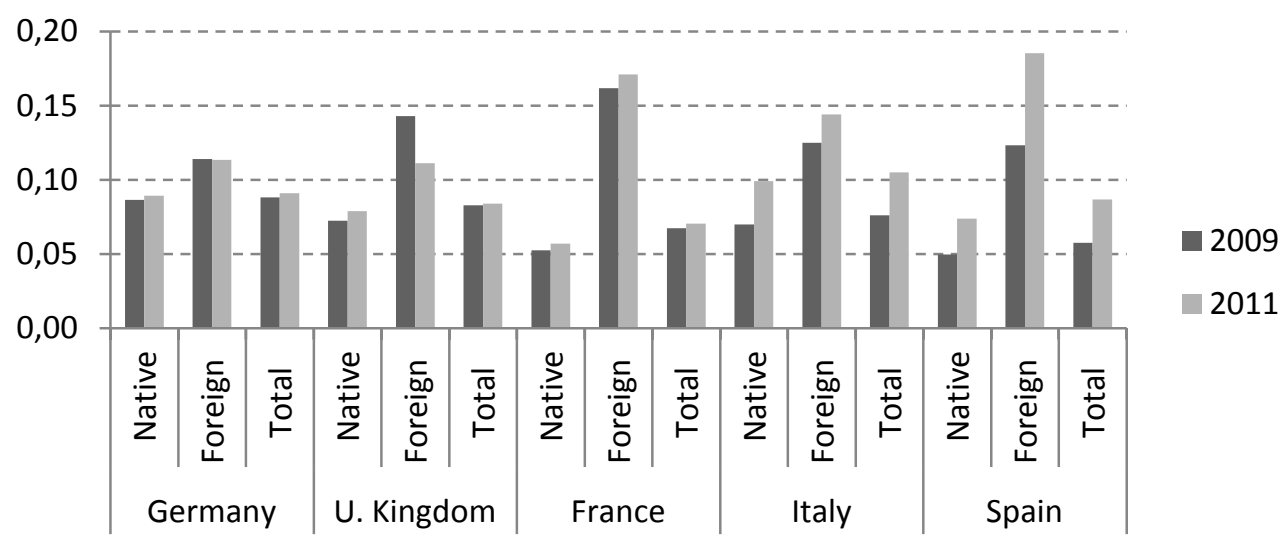

$k=3$

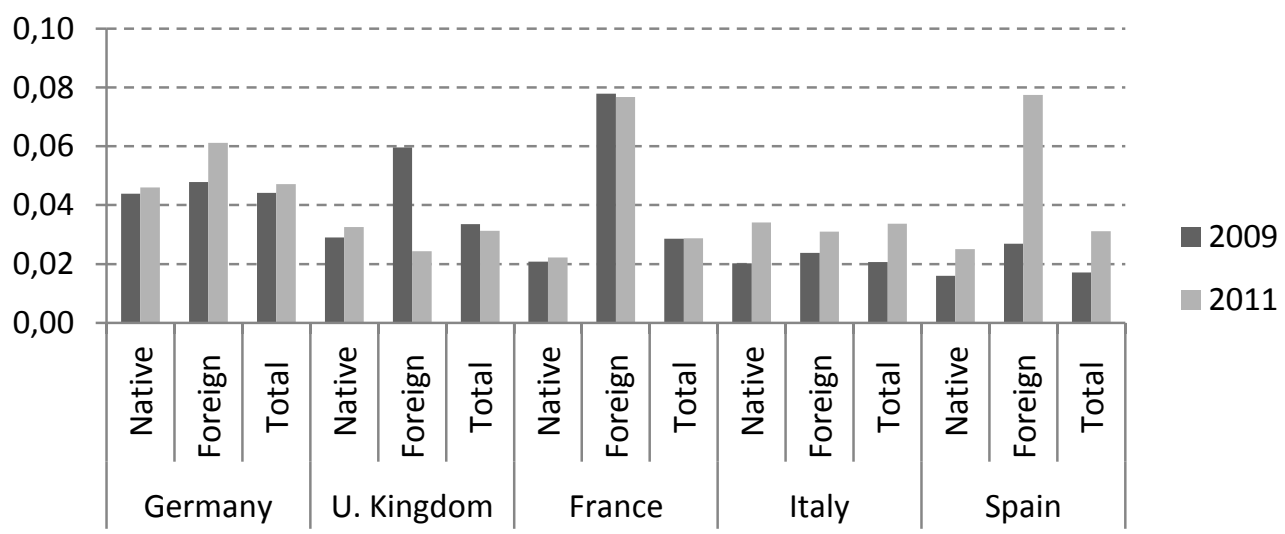

Source: Authors' elaboration, using cross-sectional 2009 and 2011 SILC anonymised user databases, versions 01-08-2011 and 01-03-13 respectively. 
Table A.8. Decomposition of the change in the Adjusted Headcount Ratio $\mathbf{M}_{0}(\mathrm{k}=2)$ between 2009 and 2011: incidence and intensity effects

\begin{tabular}{|c|c|c|c|c|c|c|}
\hline & & \multicolumn{2}{|c|}{$\Delta \mathrm{M}_{0}$} & \multicolumn{3}{|c|}{ Decomposition of change $(\%)$} \\
\hline & & Absolute & $\%$ & $\begin{array}{r}\text { Poverty } \\
\text { incidence effect }\end{array}$ & $\begin{array}{r}\text { Intensity of } \\
\text { poverty effect }\end{array}$ & Total \\
\hline \multirow[t]{3}{*}{ Germany } & Native-born & 0,00 & 3 & $90 \%$ & $10 \%$ & $100 \%$ \\
\hline & Foreign-born & 0,00 & -1 & $745 \%$ & $-745 \%$ & $100 \%$ \\
\hline & Total & 0,00 & 3 & $76 \%$ & $24 \%$ & $100 \%$ \\
\hline \multirow{3}{*}{$\begin{array}{l}\text { United } \\
\text { Kingdom }\end{array}$} & Native-born & 0,01 & 9 & $94 \%$ & $6 \%$ & $100 \%$ \\
\hline & Foreign-born & $-0,03$ & -22 & $71 \%$ & $29 \%$ & $100 \%$ \\
\hline & Total & 0,00 & 1 & $191 \%$ & $-91 \%$ & $100 \%$ \\
\hline \multirow[t]{3}{*}{ France } & Native-born & 0,00 & 8 & $102 \%$ & $-2 \%$ & $100 \%$ \\
\hline & Foreign-born & 0,01 & 6 & $123 \%$ & $-23 \%$ & $100 \%$ \\
\hline & Total & 0,00 & 5 & $114 \%$ & $-14 \%$ & $100 \%$ \\
\hline \multirow[t]{3}{*}{ Italy } & Native-born & 0,03 & 42 & $94 \%$ & $6 \%$ & $100 \%$ \\
\hline & Foreign-born & 0,02 & 15 & $94 \%$ & $6 \%$ & $100 \%$ \\
\hline & Total & 0,03 & 38 & $94 \%$ & $6 \%$ & $100 \%$ \\
\hline \multirow[t]{3}{*}{ Spain } & Native-born & 0,02 & 48 & $98 \%$ & $2 \%$ & $100 \%$ \\
\hline & Foreign-born & 0,06 & 50 & $82 \%$ & $18 \%$ & $100 \%$ \\
\hline & Total & 0,03 & 51 & $94 \%$ & $6 \%$ & $100 \%$ \\
\hline
\end{tabular}

Source: Authors' elaboration, using cross-sectional 2009 and 2011 SILC anonymised user databases, versions 01-08-2011 and 01-03-13 respectively. 
Table A.9. At risk-of-poverty or exclusion in Spain over the period 2008-2011: components and summary measures

\begin{tabular}{|c|c|c|c|c|c|}
\hline & 2008 & 2009 & 2010 & 2011 & $\begin{array}{c}\text { Ratio } \\
2011 / 2008\end{array}$ \\
\hline \multicolumn{6}{|l|}{ Total population $(<60)$} \\
\hline Low income & 0,180 & 0,183 & 0,208 & 0,221 & 1,2 \\
\hline Severe material deprivation & 0,028 & 0,038 & 0,044 & 0,042 & 1,5 \\
\hline Material deprivation & 0,093 & 0,123 & 0,141 & 0,126 & 1,4 \\
\hline Very low work intensity & 0,063 & 0,069 & 0,097 & 0,122 & 1,9 \\
\hline AROPE & 0,222 & 0,230 & 0,266 & 0,284 & 1,3 \\
\hline $\mathrm{k}=1, \mathrm{H}$ & 0,262 & 0,280 & 0,321 & 0,322 & 1,2 \\
\hline $\mathrm{k}=1, \mathrm{M} 0$ & 0,112 & 0,125 & 0,149 & 0,156 & 1,4 \\
\hline $\mathrm{k}=1, \mathrm{M} 1$ & 0,069 & 0,085 & 0,104 & 0,108 & 1,6 \\
\hline $\mathrm{k}=2, \mathrm{M} 0$ & 0,046 & 0,057 & 0,075 & 0,087 & 1,9 \\
\hline $\mathrm{k}=2, \mathrm{M} 1$ & 0,032 & 0,041 & 0,053 & 0,063 & 2,0 \\
\hline $\mathrm{k}=3, \mathrm{M} 0$ & 0,012 & 0,017 & 0,027 & 0,031 & 2,6 \\
\hline $\mathrm{k}=3, \mathrm{M} 1$ & 0,009 & 0,013 & 0,020 & 0,024 & 2,5 \\
\hline \multicolumn{6}{|l|}{ Total immigrants $(<60)$} \\
\hline Low income & 0,303 & 0,300 & 0,315 & 0,376 & 1,2 \\
\hline Severe material deprivation & 0,101 & 0,116 & 0,142 & 0,113 & 1,1 \\
\hline Very low work intensity & 0,039 & 0,068 & 0,120 & 0,174 & 4,5 \\
\hline Material deprivation & 0,273 & 0,319 & 0,339 & 0,303 & 1,1 \\
\hline AROPE & 0,370 & 0,378 & 0,395 & 0,442 & 1,2 \\
\hline $\mathrm{k}=1, \mathrm{H}$ & 0,462 & 0,489 & 0,500 & 0,536 & 1,2 \\
\hline $\mathrm{k}=1, \mathrm{M} 0$ & 0,205 & 0,229 & 0,258 & 0,284 & 1,4 \\
\hline $\mathrm{k}=1, \mathrm{M} 1$ & 0,134 & 0,162 & 0,191 & 0,201 & 1,5 \\
\hline $\mathrm{k}=2, \mathrm{M} 0$ & 0,097 & 0,123 & 0,165 & 0,185 & 1,9 \\
\hline $\mathrm{k}=2, \mathrm{M} 1$ & 0,067 & 0,084 & 0,120 & 0,136 & 2,0 \\
\hline $\mathrm{k}=3, \mathrm{M} 0$ & 0,013 & 0,027 & 0,057 & 0,077 & 6,1 \\
\hline $\mathrm{k}=3, \mathrm{M} 1$ & 0,010 & 0,020 & 0,044 & 0,059 & 5,9 \\
\hline \multicolumn{6}{|l|}{ Immigrants $(<25)$} \\
\hline Low income & 0,397 & 0,369 & 0,384 & 0,430 & 1,1 \\
\hline Severe material deprivation & 0,111 & 0,139 & 0,179 & 0,129 & 1,2 \\
\hline Material deprivation & 0,296 & 0,361 & 0,391 & 0,323 & 1,1 \\
\hline Very low work intensity & 0,036 & 0,067 & 0,121 & 0,170 & 4,8 \\
\hline AROPE & 0,448 & 0,443 & 0,454 & 0,496 & 1,1 \\
\hline $\mathrm{k}=1, \mathrm{H}$ & 0,537 & 0,547 & 0,554 & 0,577 & 1,1 \\
\hline $\mathrm{k}=1, \mathrm{M} 0$ & 0,243 & 0,266 & 0,299 & 0,308 & 1,3 \\
\hline $\mathrm{k}=1, \mathrm{M} 1$ & 0,147 & 0,181 & 0,215 & 0,212 & 1,4 \\
\hline $\mathrm{k}=2, \mathrm{M} 0$ & 0,124 & 0,156 & 0,204 & 0,203 & 1,6 \\
\hline $\mathrm{k}=2, \mathrm{M} 1$ & 0,083 & 0,104 & 0,147 & 0,148 & 1,8 \\
\hline $\mathrm{k}=3, \mathrm{M} 0$ & 0,010 & 0,032 & 0,072 & 0,084 & 8,3 \\
\hline $\mathrm{k}=3, \mathrm{M} 1$ & 0,007 & 0,023 & 0,055 & 0,065 & 8,8 \\
\hline
\end{tabular}

Source: Authors' elaboration, using cross-sectional 2008, 2009, 2010 and 2011-SILC anonymised user databases, versions 01-08-2011 for 2008 and 2009, 01-03-12 for 2010 and 01-03-13 for 2011. 